\title{
Finite Element Simulation of Deep Drawing of Aluminium Alloy Sheets
}

\author{
Shaik Himam Saheb ${ }^{1}$, M. Sree Hari ${ }^{2}$, Annam Vijay Kumar ${ }^{2}$ \\ ${ }^{1}$ Department of Mechanical Engineering, ICFAI University, Hyderabad, India \\ ${ }^{2}$ Department of Mechanical Engineering, Gurunanak Institutions, Hyderabad, India \\ Email address: \\ Himam.mech@gmail.com (S. H. Saheb)
}

\section{To cite this article:}

Shaik Himam Saheb, Annam Vijay Kumar. Finite Element Simulation of Deep Drawing of Aluminium Alloy Sheets. International Journal of Industrial and Manufacturing Systems Engineering. Vol. 2, No. 6, 2017, pp. 83-102. doi: 10.11648/j.ijimse.20170206.13

Received: October 5, 2017; Accepted: November 1, 2017; Published: January 16, 2018

\begin{abstract}
More and more automobile companies are going for weight reduction of their vehicles for fuel economy and pollution control. The objective of the present study is to determine the effect of blank temperature on forming behaviour of sheets and damage factor of aluminium sheet alloys of 6061 and 7075 at elevated temperatures. Although the aluminium alloys have high-strength to weight ratio and good corrosion resistance, the low formability of aluminium sheets limits their use in some products with complex shapes, such as automotive body parts. The elevated forming process is intended to overcome this problem. An insight into such a study will throw light on the different temperatures required by the above materials when they are made into TWBs. Using ANSYS a series of simulations were carried out in the present investigation on the formability behaviour of deep drawing of aluminium alloys in the temperature range $200-500^{\circ} \mathrm{C}$.
\end{abstract}

Keywords: Aluminium Alloys, Forming, Damage Factor, ANSYS

\section{Introduction to Forming Processes}

Casting, machining, welding and metal forming are the main methods of manufacturing. The other methods of manufacturing are powder metallurgy, heat treatment and finishing. In casting a liquid material is poured into a mold and then allowed to solidify in order to take the desired shape. By casting, big and complex parts can be manufactured. The second manufacturing process is machining. This process can be defined as removing material (chips) from the workpiece. Machining is one of the most used processes in manufacturing. Cutting tool is used for removing material from the piece while cooling fluid dissipates the heat generated from the process. Another method is welding. In this method, two or more metal pieces are joined together by melting or fusing them with the help of heat. Welding is generally used in shipbuilding, automotive manufacturing and aerospace applications. The last method is metal forming. In this process, applying force to the piece forms the material shape. Metal forming is used for achieving complex shape products and improving the strength of the material. During forming, little material is wasted compare to other manufacturing processes. Bulk forming and sheet metal working are the two main groups of forming processes based on raw material used in the process. Rolling, forging and extrusion in bulk forming can be done cold, warm and hot. The other forming process is sheet metal forming. In this method, applying pressure through dies shapes thin sheets of metal. Sheet metal forming is very important for metals because nearly $50 \%$ of metals are produced in sheet metals.

Sheet metal forming is done by many ways such as shearing and blanking, bending stretching, spinning and deep drawing. Those methods are widely used for producing various products in different places of industry. The parts manufactured by sheet metal forming are widely used in automotive and aircraft industries.

Deep drawing is one of the most important sheet metal forming processes. A 2-d part is shaped into a 3-d part by deep drawing. According to the definition in DIN 8584, "deep drawing is the tensile-compressive forming of a sheet blank to a hollow body open on one side or the forming of a pre-drawn hollow shape into another with a smaller crosssection without an intentional change in the sheet thickness." 

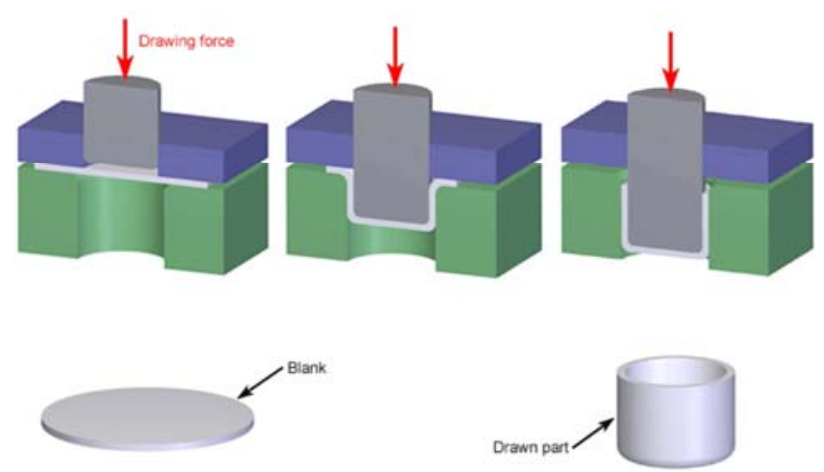

Figure 1. Showing Conventional Deep Drawing Process.

\section{Objective of the Project}

It is well known that the ductility of aluminium alloy sheets can be improved notably with increase in the working temperature. Warm forming is one of the ways to obtain high formability in aluminium sheets. The objective of the present study is to determine the effect of blank temperature on forming behaviour of sheets of such aluminium sheet alloys of 6061 and 7075 at elevated temperatures. In the present investigation, a series of simulations were carried out on the formability behaviour of deep drawing of aluminium alloys in the temperature range $200-500^{\circ} \mathrm{C}$ using ANSYS.

\section{Deep Drawing Process}

As mentioned in the introduction chapter, flat sheet of metal is formed into a 3-d product by deep drawing process. The main tools of the process are blank, punch, die and blank holder. In the simple circular cup drawing process with blank holder, the tools and tool geometries are shown in the Figure

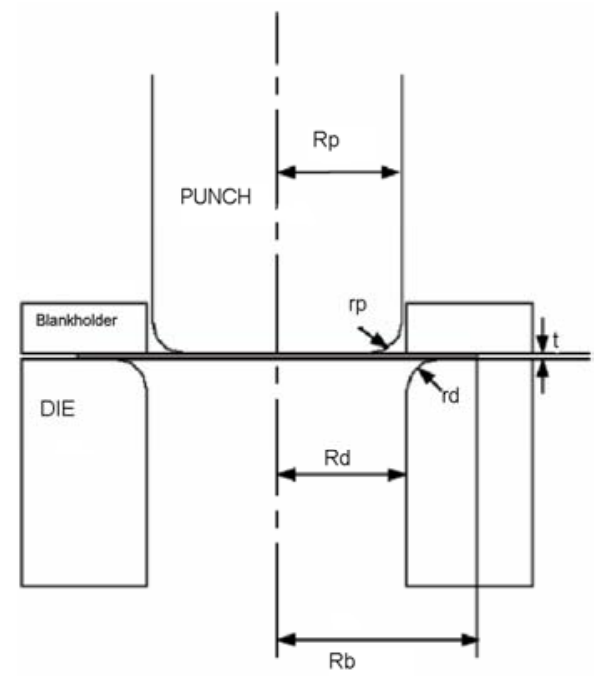

Figure 2. Showing Geometry parameters for deep drawing tools.

The tool geometry parameters are:

1. Punch Radius $R_{p}$
2. Punch Edge Radius $r_{p}$

3. Blank Thickness $t$

4. Blank Radius $R_{b}$

5. Die Radius $R_{d}$

6. Die Edge Radius $r_{d}$

These parameters must be selected very carefully because the final product highly depends on these geometries. Shape of the fully drawn cup is obtained by selecting die and punch respectively. Clearance is also an important parameter, formulated as the difference between die radius and punch radius $(c=R d-R p)$. If the clearance is not large enough, ironning will occur. Ironning is defined as thinning of the blank at the die cavity. In order to eliminate this problem, clearance should be $25 \%$ larger than the initial blank thickness. Also the punch edge radius and die edge radius effects the process. Larger corner radius lowers the punch load whereas smaller radius increases the needed punch load.

In addition to the tool geometry parameters, there are also physical parameters in drawing operations. Some of these are

1. Blank material properties

2. Blank holder force

3. Punch speed

4. Lubrication

5. Draw depth

\section{Stress Zones During Deep Drawing}

Deep drawing process is defined as a tensile-compressive forming of the sheet metal in the literature. During the deep drawing process, due to punch force and blank holder force, different stress zones are formed. Four different states can be defined as Force application zone, Force transmission zone, bending zone and forming zone that can be seen from the Figure

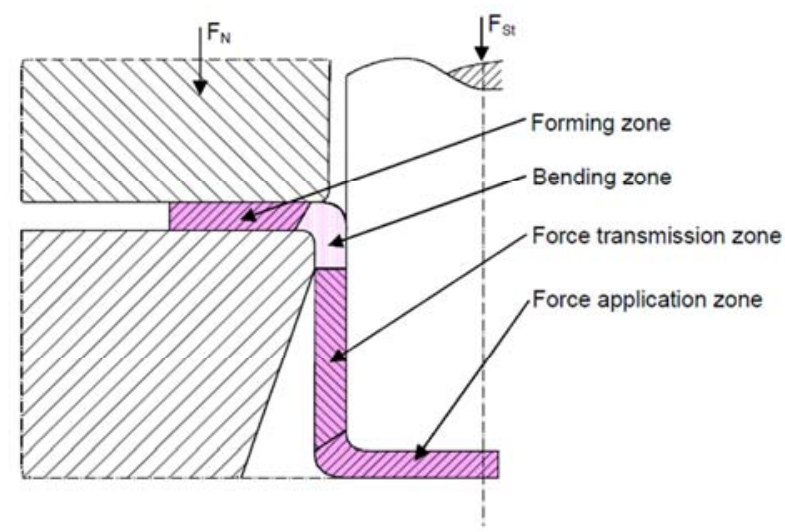

Figure 3. Showing Four different zones in deep drawing.

The punch force is applied onto the bottom of the drawn part, which is called the force application zone. Then it is transferred to the flange region. The force is transmitted along the wall of the cup. Bending happens over the die edge radius and forming takes places in the flange region. 


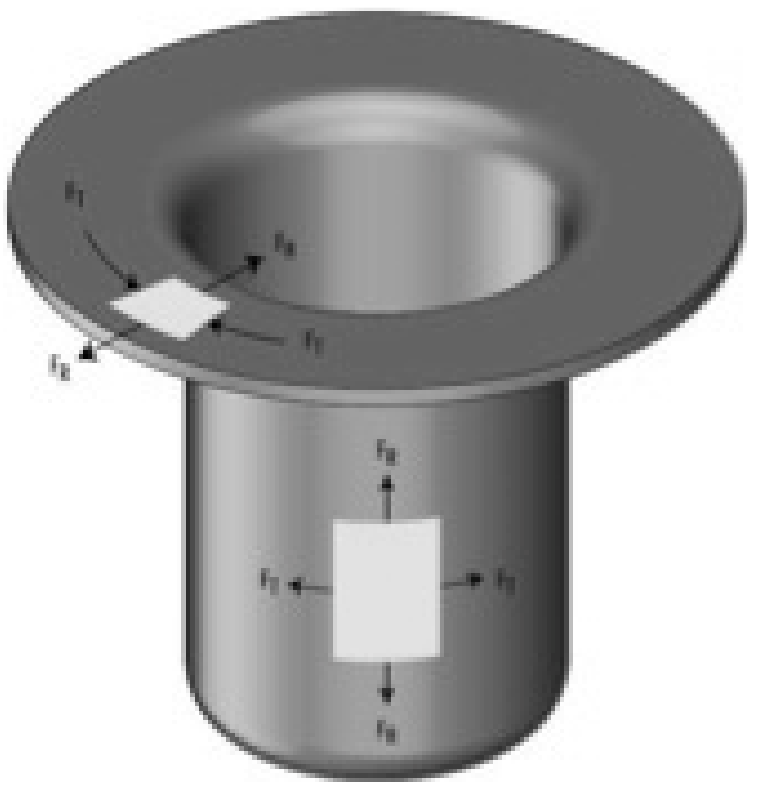

Figure 4. Showing pressure forces in deep drawing of a round cup with a blank holder.

The workpiece is subjected to radial tension forces FR and tangential compression forces FT during the process (Figure). The material is compressed in the tangential direction and stretched in the radial direction. As it can be seen from the figure above, there are compressive forces in the flange region and tensile forces elsewhere in the workpiece.

Over the punch head, force application zone, sliding and stretching of the material occurs. In this region, material gets thinner because of stretching. The limiting drawing ratio (LDR), will be discussed later, depends on the load carrying capacity of this zone. The maximum load carrying capacity is determined by the plastic instability-taking place in this region. However, plastic instability depends on the friction properties between the punch and blank. Equal-biaxial tensile stresses act in this region.

In the region between die and punch, force transmission zone, generally there is no contact of the material with either of punch and die. This is a transition region between die and punch. In this region radial tensile stresses act on the material. Material gets thinner and tearing or necking can take place in this region.

Over the die edge radius, sliding and bending of the material occurs. In this region, in the radial direction tensile stresses occurs, whereas compressive stress is observed in the circumferential direction. As mentioned before, radius of the curvature of die profile has effect on the punch load. For a sharper radius more plastic bending work is done, therefore the punch load increases. In the bending region, material gets thinner due to bending under tensile stresses in the radial direction.

As the draw depth is increased, the amount of deformation and the deformation resistance are also increased. The sheet metal is most severely stretched in the corner of the draw punch, corresponding to the tip of the drawn cup. Failure normally occurs at this region of the blank.
Since there is a strongly non-homogeneous deformation throughout the part, residual stresses arise. Residual tension is observed on the outside whereas residual compression occurs in the inside of the part over the die lip in axial direction. Bending causes these residual stresses and unbending action happened over the die. Through the wall of the drawn part, residual stresses takes its largest value near the top of the wall, near the intersection area of wall and die lip, due to bending. The wall of the part is subjected to bending moment because of residual stresses. This moment is leveled by the hoop tension, occurring at the top of the cup. Hoop tension can cause stress corrosion cracking at the transmission zone (wall) in some metal materials. Owing to the presence of residual stresses, deep drawn parts are sensitive to successive operations. A workpiece may distort or fracture upon machining operations and heat treatments may cause the part to change shape.

\section{Anisotropy}

Due to their crystallographic structure and the characteristic of the rolling process, sheet metals generally exhibit a significant anisotropy of mechanical properties. The variation of their plastic behavior with direction is assessed by a quantity called Lankford parameter of anisotropy coefficient. This coefficient is usually obtained by uniaxial tensile tests on strip shaped sheet specimens. The anisotropy coefficient ( $\mathrm{r}$ ) is defined by

$$
r=\frac{\varepsilon_{2}}{\varepsilon_{3}}
$$

Where, $\varepsilon_{2}$ is the strain in the width direction and $\varepsilon_{3}$ is in the thickness direction.

Experiments show that $r$ depends on the in-plane direction. If the tensile specimen is cut having its longitudinal axis parallel to the rolling direction, the coefficient $r_{90}$ is obtained. The average of the r-values obtained for different directions in the plane of the sheet metal represents the coefficient of normal anisotropy $r_{n}$.

The coefficient of normal anisotropy is obtained from equation

$$
\mathrm{r}_{\mathrm{n}}=\frac{r_{0}+2 \cdot r_{45}+r_{90}}{4}
$$

Where

$\mathrm{r}_{0}$ is anisotropy factor in rolling direction

$r_{45}$ is anisotropy factor in $45^{\circ}$ direction relative to rolling direction

$\mathrm{r}_{90}$ is anisotropy factor in $90^{\circ}$ direction relative to rolling direction

A material with a high rn value will experience less thinning during a deep drawing operation than a material having a smaller $\mathrm{rn}$ value, provided that their flow characteristics are identical. For instance, aluminum usually has an $\mathrm{r}$ value smaller than 1 (about 0.6 ), whereas steel has an rn value larger than 1 (about 1.5). 


\section{The Limiting Drawing Ratio}

The limiting draw ratio is the ratio of the diameter of the initial blank form to the diameter of the drawn part. LDR is an important numerical value for cylindrical draw parts in determining the required number of drawing steps. For cylindrical cup drawing process with circular cross-section, drawing ratio can be defined by the following equation:

$$
\mathrm{LDR}=\frac{d_{0 . M A X}}{d_{p}}
$$

The drawing ratio is dependent on many factors like the tool geometry, lubrication conditions, and the amount of blank holding forces, sheet thickness, and material properties (especially the $\mathrm{r}$ and $\mathrm{n}$ value). The limiting drawing ratio (LDR), which can be reached in a single drawing step, is theoretically calculated by membrane analysis. The ideal limiting drawing ratio found from the membrane theory is

$$
\mathrm{LDR}_{\mathrm{MAX}} \leq \mathrm{e} \approx 2.72
$$

In reality the LDR for aluminum sheets are 1.8 to 2.0. This value is around 1.9 to 2.2 for steel sheets. The reason for this is various process parameters are not considered in the simplifying membrane theory. For any material in a deep drawing operation, a higher LDR means that 'deeper' drawings are possible, whereas a lower LDR restricts the deep drawability. The LDR is strongly material dependent and for several materials the effect of average strain ratio on LDR can be seen from the Figure

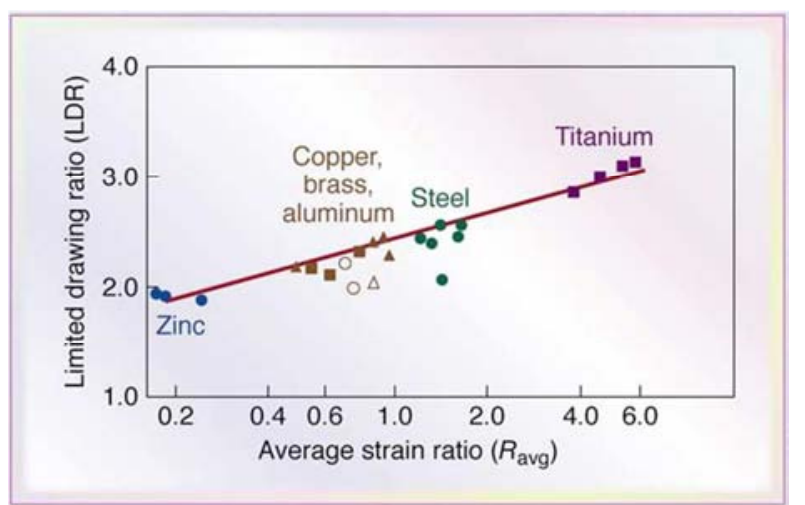

Figure 5. Showing Effect of average strain ratio on LDR for different materials.

When the friction between the blank and the punch is low, then failures will occur in the base of the part. If the friction between the part and the punch is high, the base of the drawn part will be increasingly stressed with increasing friction in the can body so that the failure zone will be moved to the body of the drawn can. In order to ensure a safe production process, it is preferable to select a draw ratio that is rather modest and less than the maximum possible value.

\section{Formability of Sheet Metals}

At the end of the nineteenth century, due to the development of the sheet forming technology, sheet metal formability became a research topic. Some of the first researchers interested in this field were Bessemer and Parkers, Adamson, Considere and Erichsen.

The formability of sheet metals is affected by many parameters, like material parameters, process parameters and strain bounding criteria. Above Figure summarizes the parameters that have an effect on the formability of sheet metals.

\section{Neccesity of Aluminum}

Now a days, there is a great concern about weight reduction of automobile due to increased production of aluminium alloy with better formability. Aluminium alloy sheets are being widely employed in making components for automobile and shipbuilding due to their excellent properties such as high specific strength, corrosion resistance and weldability.

\section{Limitations}

Although cast aluminium alloys are being employed for a considerable number of components, the use of forming products of aluminium alloy sheets is still limited because the formability of aluminium alloy sheet is still poor due to lack of understanding of flow behavior during deformation.

\section{Steps Involving in Solving a Problem Using Ansys}

To solve ANSYS problem analytically, we need to define.

1. Solution domain

2. Solution domain

3. Physical model

4. Boundary condition

5. Physical properties

After these steps problem is solved and solution is obtained

The main difference between solving a problem analytically \& using the software is that software enables the creation of mesh. This is the extra step that is implemented in solving a problem. The step divides the complex model into small elements that become solvable.

There are three major steps in solving a problem in ANSYS.

1. Pre -processor

2. Solution

3. Post-processor

a. Pre -processor stage containing building of geometry defining element type $\&$ material properties, generation of mesh.

b. Solution stage contains applying loads \& boundary condition $\&$ defining the analysis type.

\section{Methodology}

In this study, V-cup drawing simulations were performed. 
All the simulations were performed with blank of $20 \mathrm{~mm}$ diameter with $5 \mathrm{~mm}$ thick sheets of aluminium 6065 and 7075 sheets. The motion at both the ends of blank are constrained in both $\mathrm{X}$ and $\mathrm{Y}$ directions. For each material a series of cups were drawn at temperature range $200-5000^{\circ} \mathrm{C}$.

In this project, deep drawing study has been performed using ANSYS for determining the formability behaviour of aluminium alloys at elevated temperatures and a set of results have been formulated.

Now a days, designers and manufacturers are preferring simulation of process before implementation of actual process as this provides more information related to the process performance to evaluate the effect of different process variables during process that result in saving material and manufacturing cost. In this context, a deep drawing model has been formulated using finite element code.

The first main step is selection of model type. As simulation of deep drawing is structural type, therefore structural analysis is selected. A solid brick of 8 node 185 model has been created using element type. Solid brick is directly selected to make problem simple and easy. Before creating the volume of required model, material properties like Young's modulus, Poisson's ratio, Density and Secant co-efficient should be given. To solve fem oriented problem suitable material properties are required. After material properties are given volume is created directly with required values, since the element type is solid brick.

Geometric modelling is done in pre processing step. Analysing and solution is done in post processing step. All the results are autosaved in post processor of the software.

\section{Results and Discussions}

Solutions in ANSYS provide the ability to simulate every structural aspects of a product, including linear static analysis that simply provides stress or deformations. The fidelity of the results is achieved through the wide variety of material models available, the quality of the elements library, the robustness of the solution algorithms and the ability to model every product, from single parts to very complex assemblies with hundreds of components interacting through contacts or relative motions.

Each color in deformation and stress intensity nodal solution represents the damage level. Where blue represents minimum damage and red represents maximum damage at required nodes. After meshing i.e. element will be discretization. Therefore at each node the solution will be displayed in $\mathrm{X}, \mathrm{Y}, \mathrm{Z}$ directions.

\section{Results for Aluminium - 6065}

At $200^{\circ} \mathrm{C}$

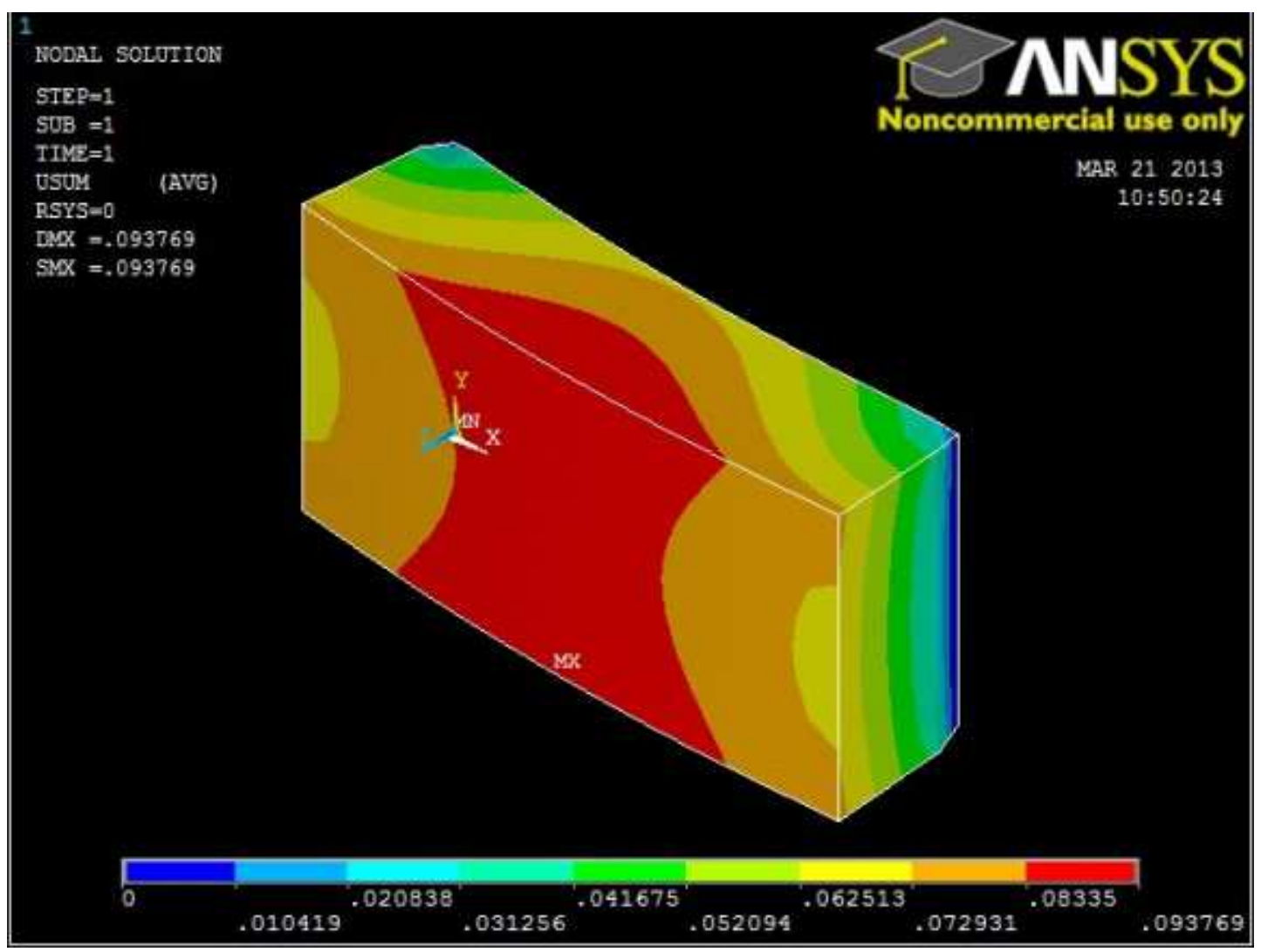

Figure 6. Showing Deformation of aluminium at At $200^{\circ} \mathrm{C}$. 


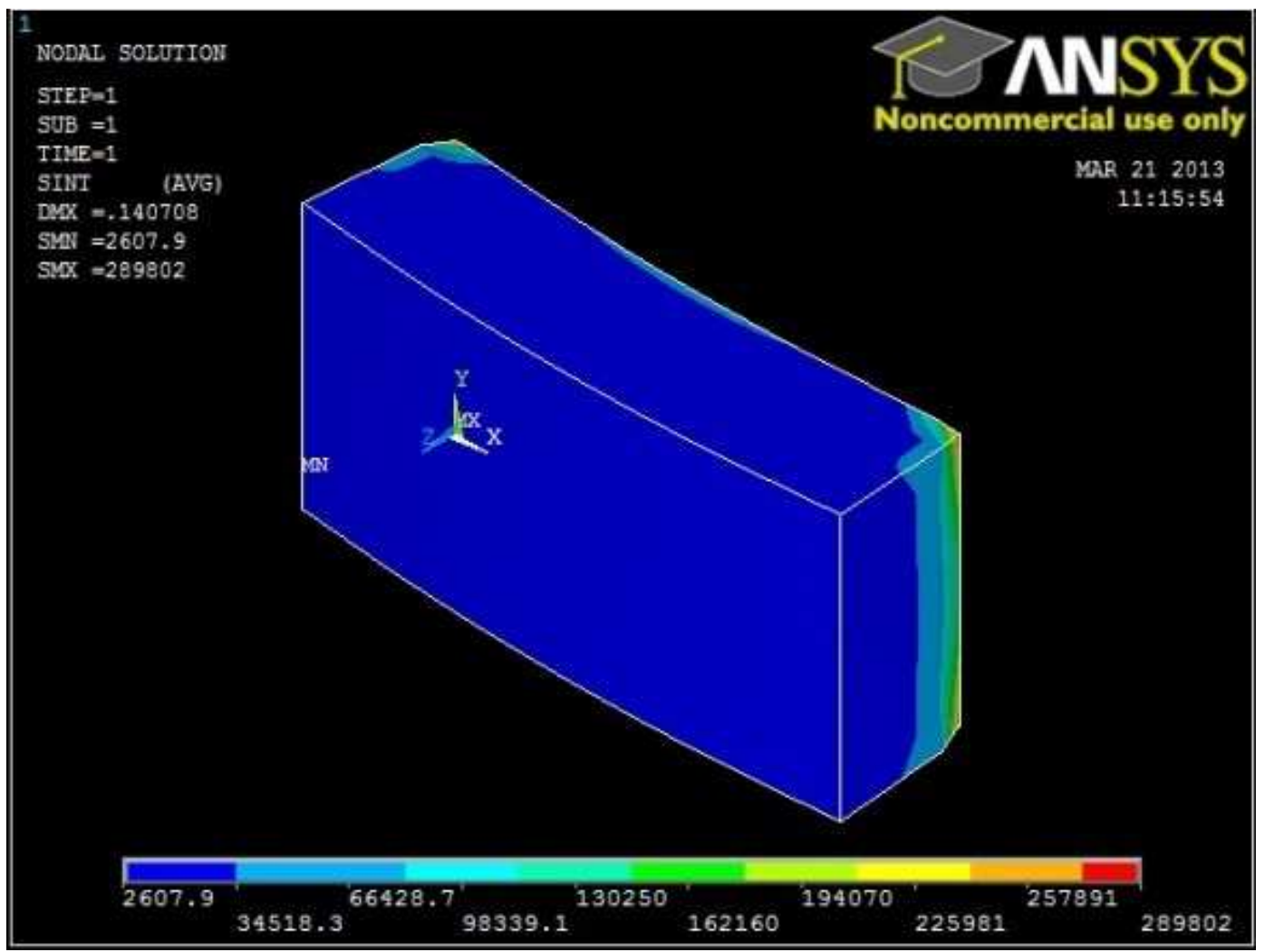

Figure 7. Showing Stress Intensity of aluminium at At $200^{\circ} \mathrm{C}$.

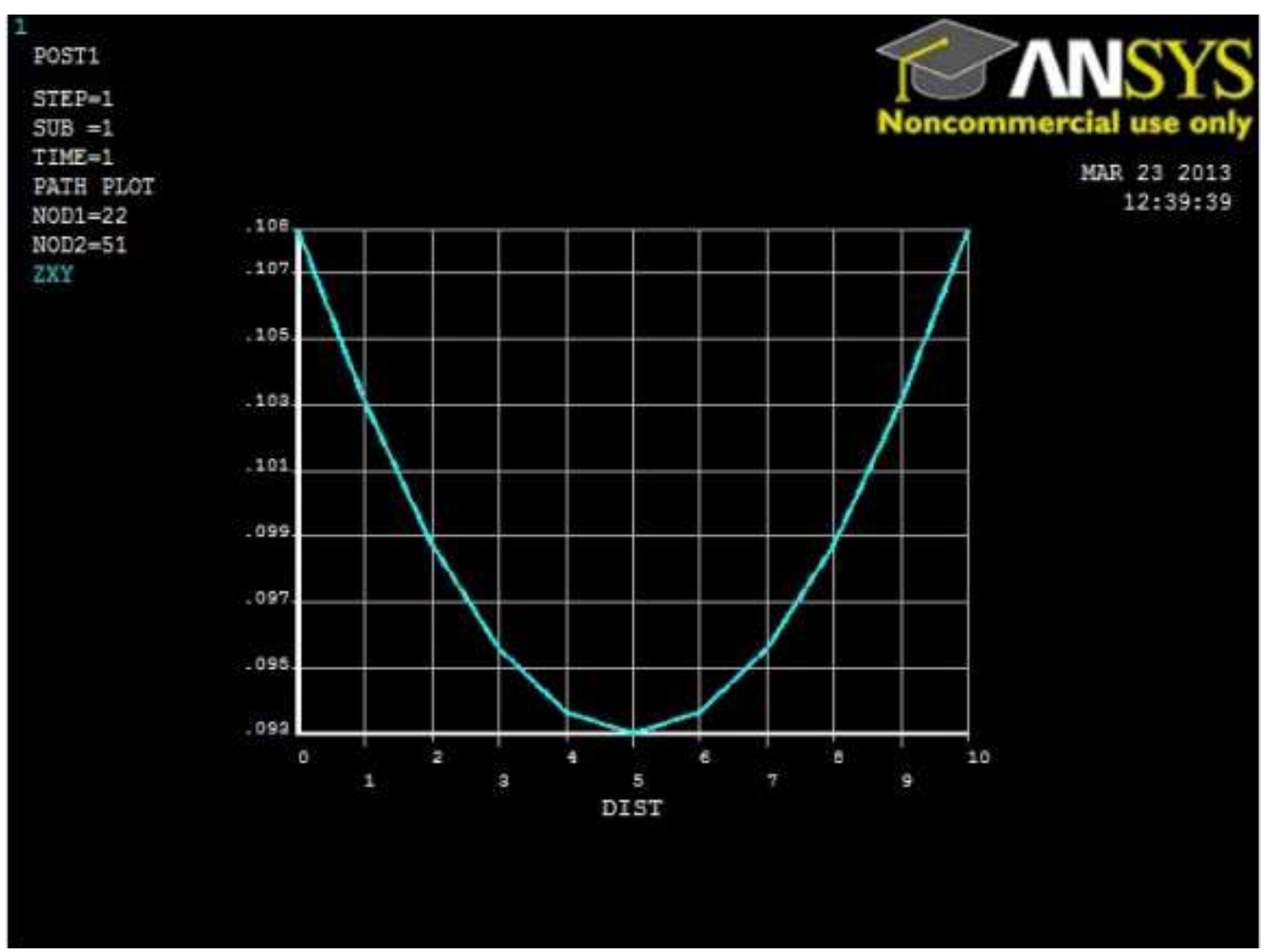

Figure 8. Showing Distance Vs Deflection graph of aluminium at At $200^{\circ} \mathrm{C}$. 


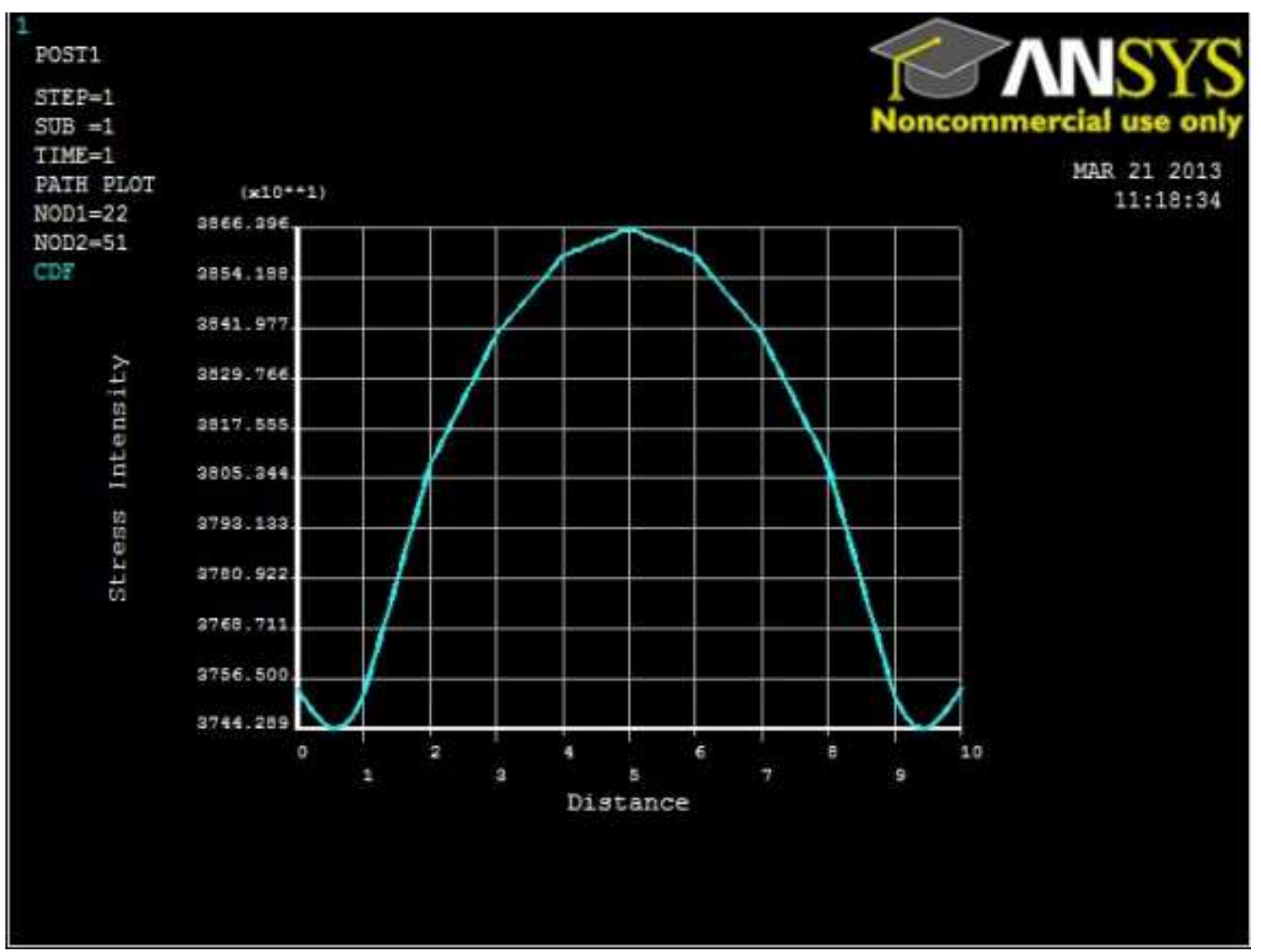

At $400^{\circ} \mathrm{C}$

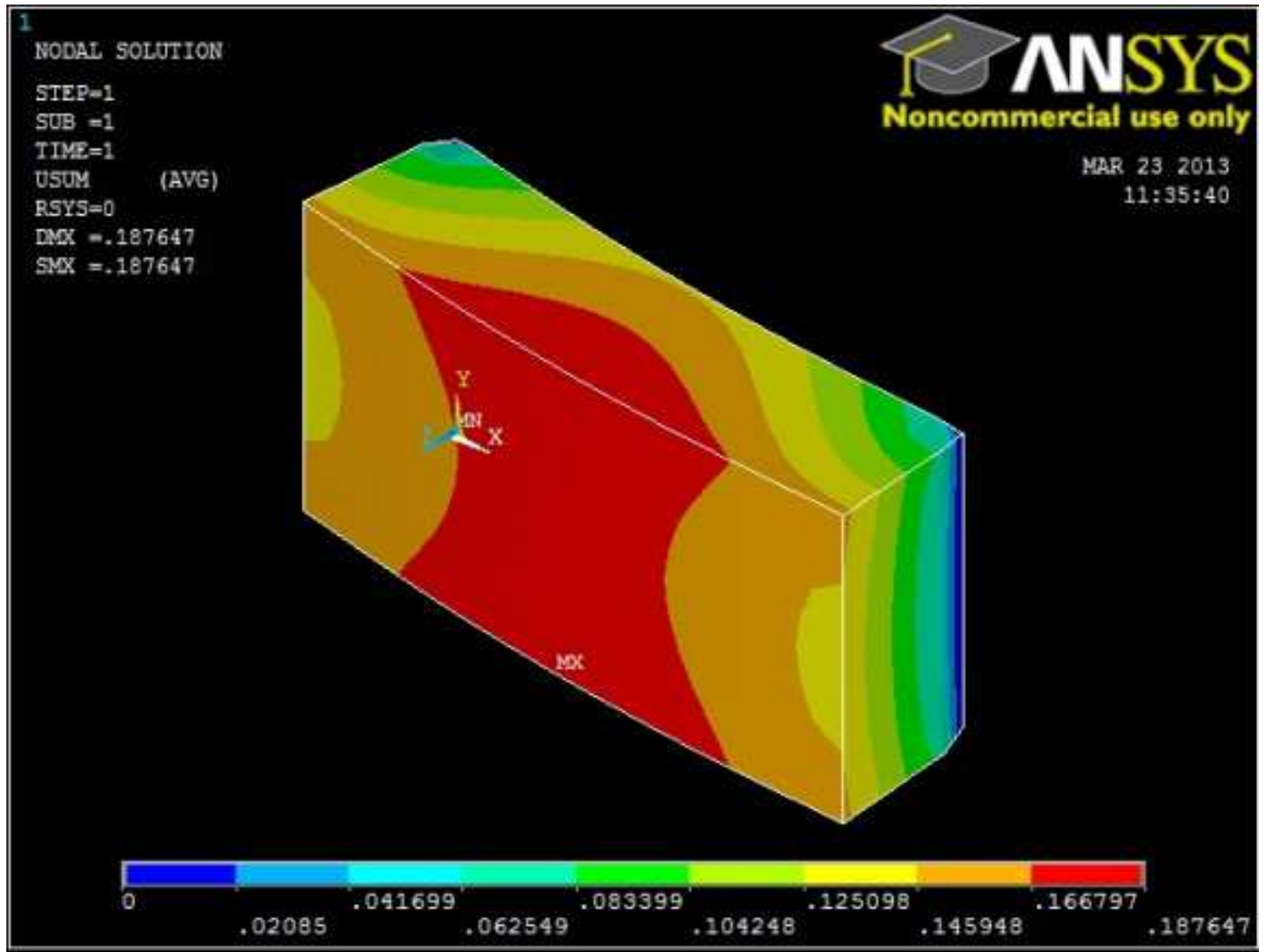

Figure 9. Showing deformation of aluminium at $\mathrm{At} 400^{\circ} \mathrm{C}$. 


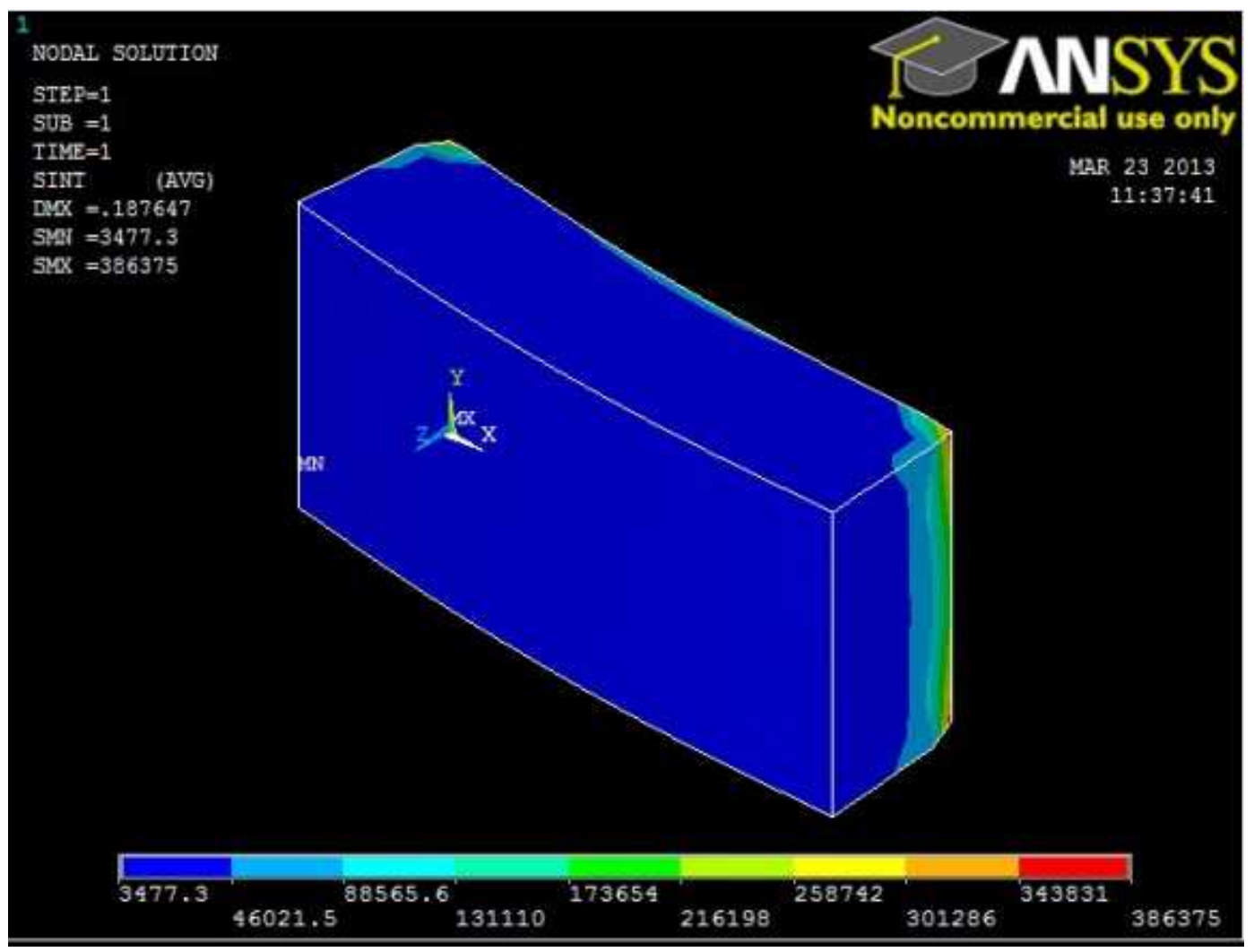

Figure 10. Showing Stress Intensity of aluminium at At $400^{\circ} \mathrm{C}$.

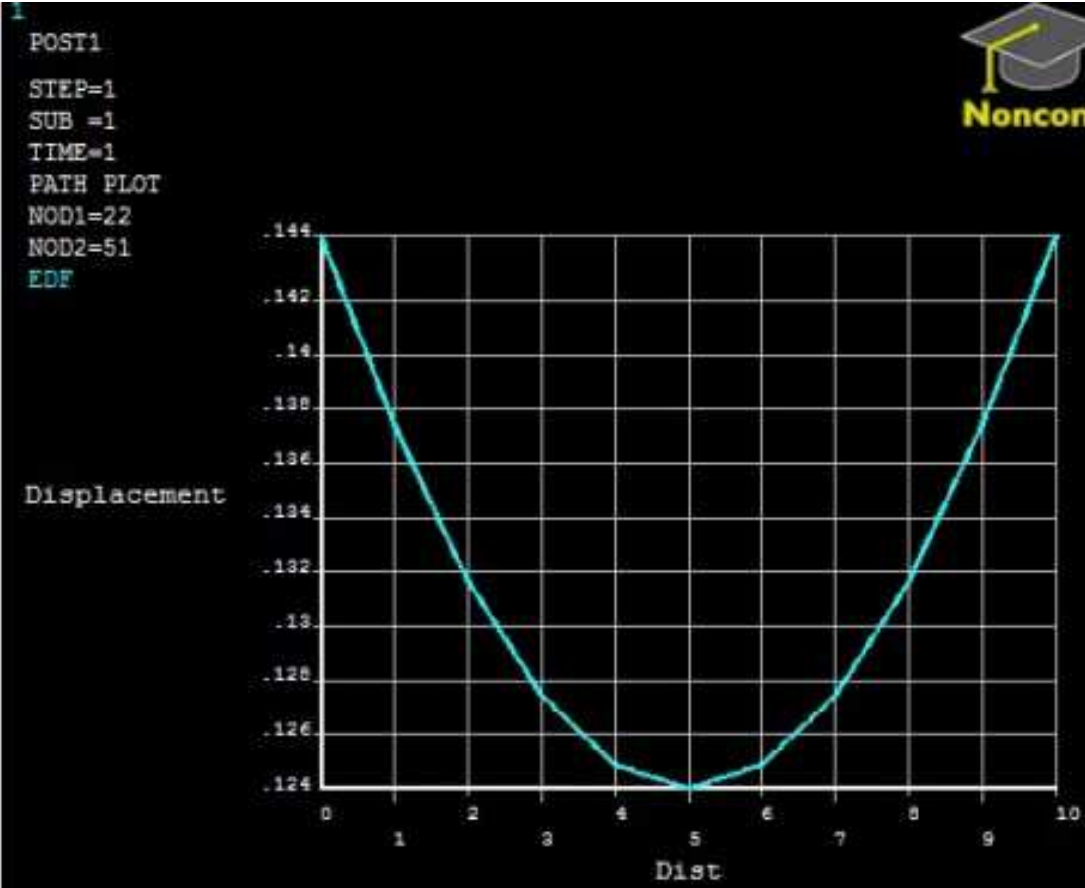

Figure 11. Showing Distance Vs Deflection. 


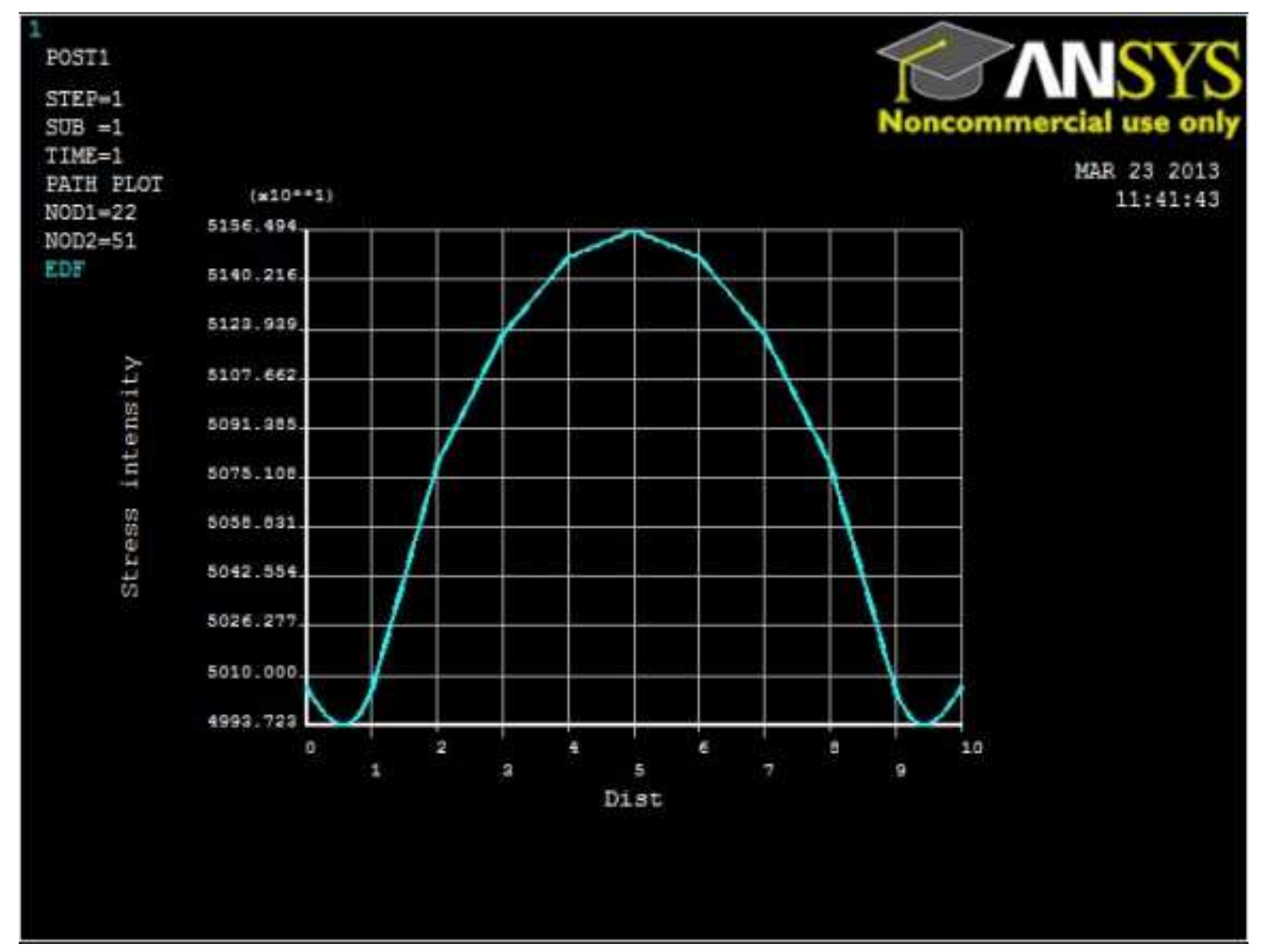

Figure 12. Distance Vs Stress Intensity.

At $500^{\circ} \mathrm{C}$

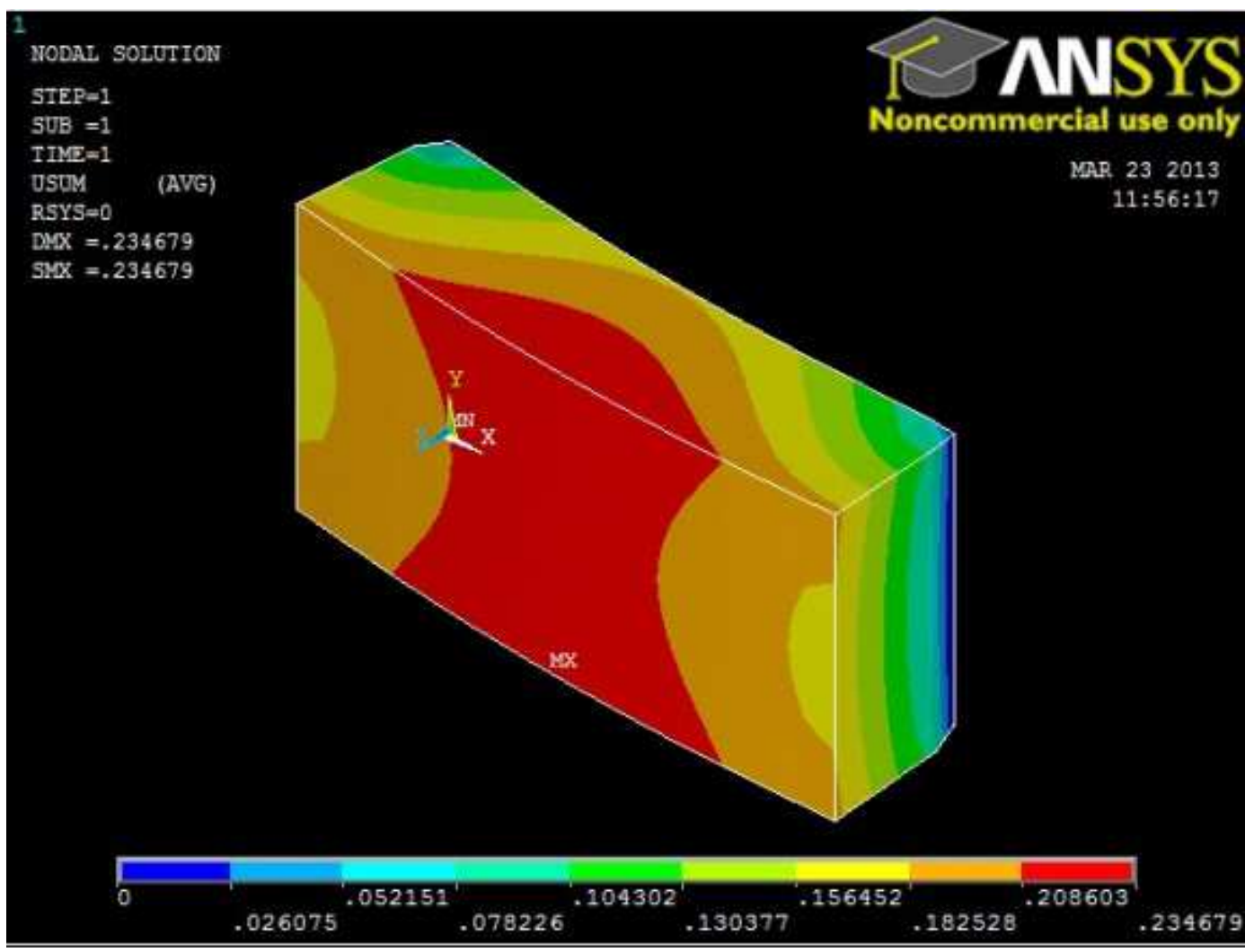

Figure 13. Showing Deformation of aluminium at At $500^{\circ} \mathrm{C}$. 


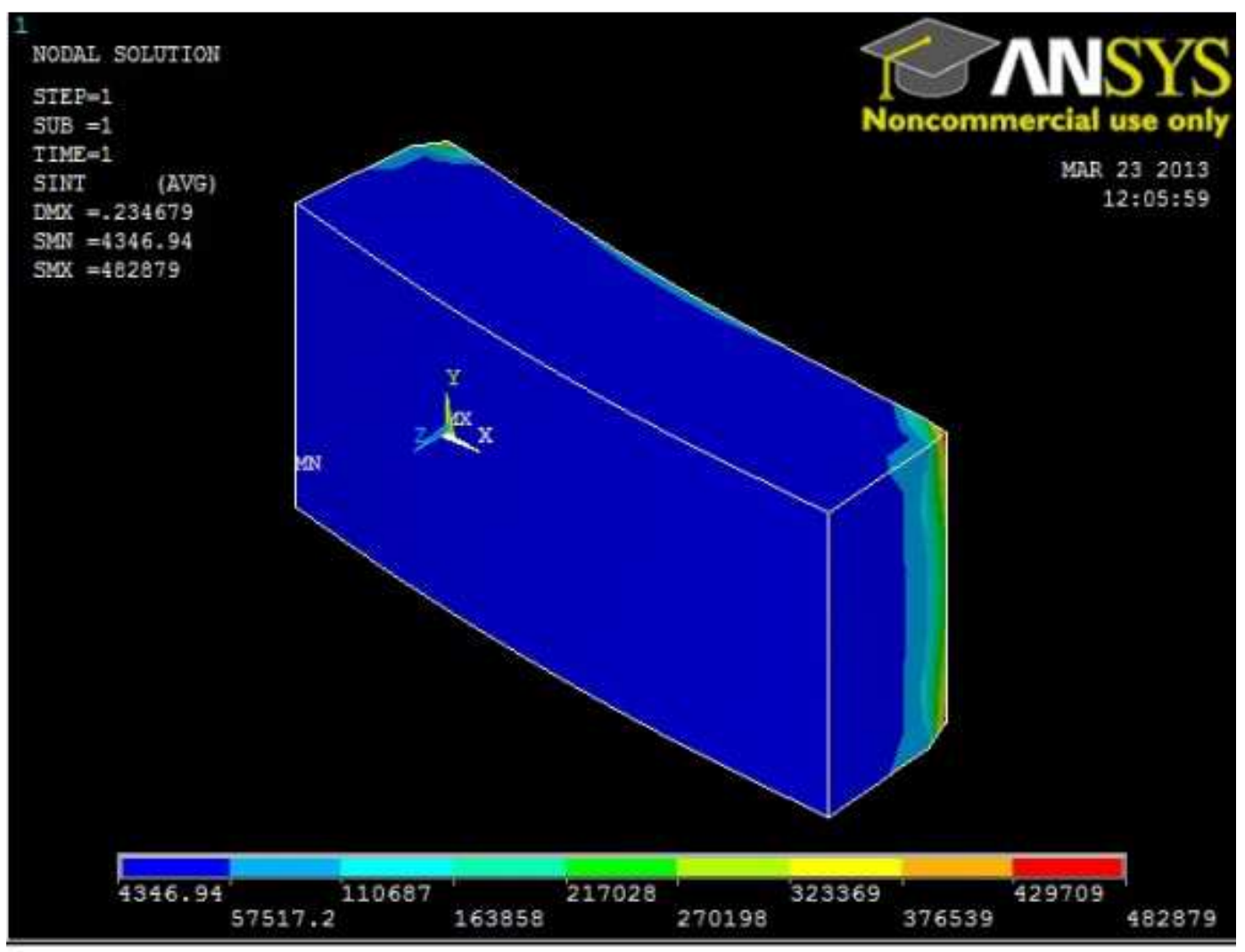

Figure 14. Showing Stress Intensity of aluminium at At $500^{\circ} \mathrm{C}$.

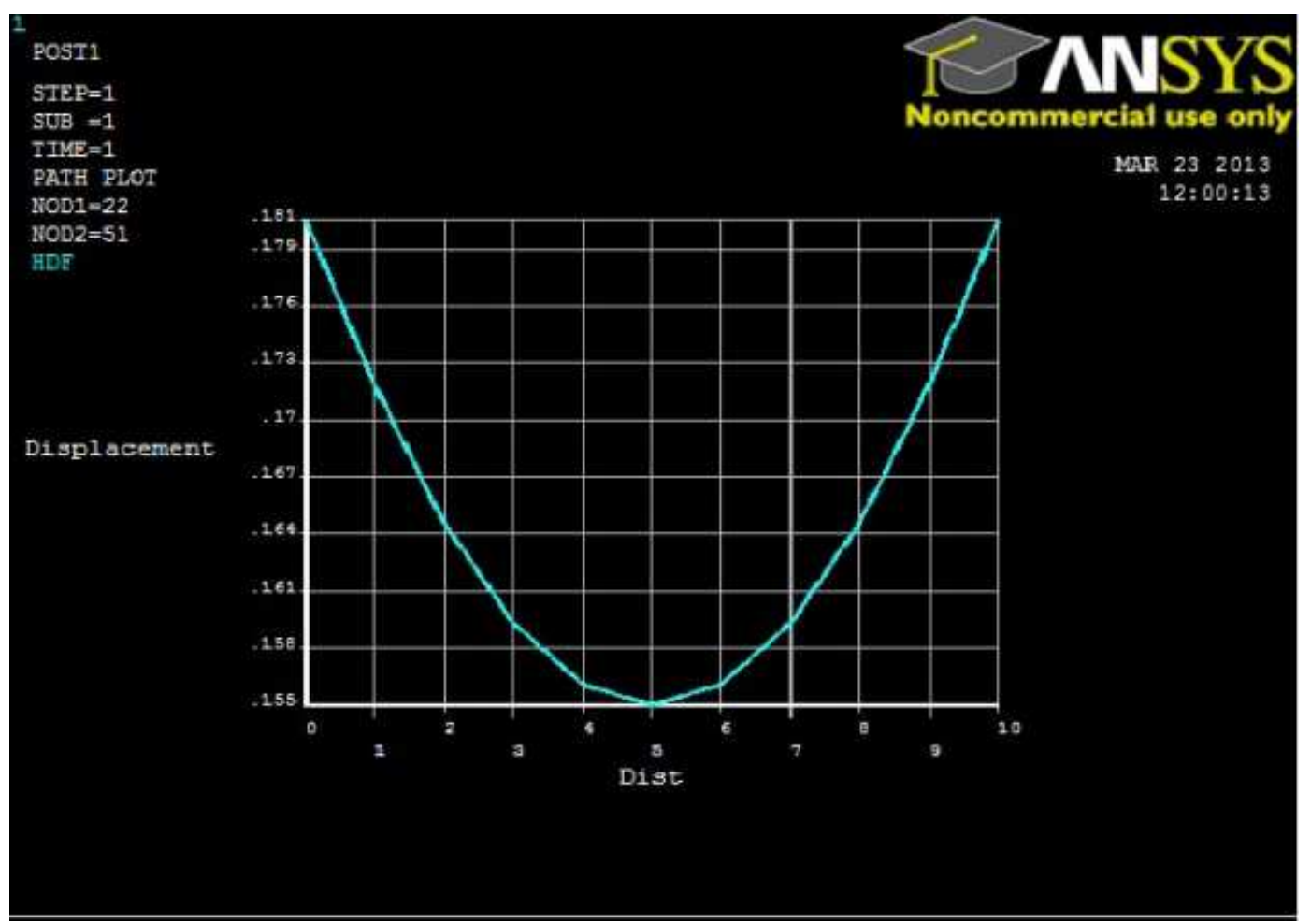

Figure 15. Distance Vs Deflection. 


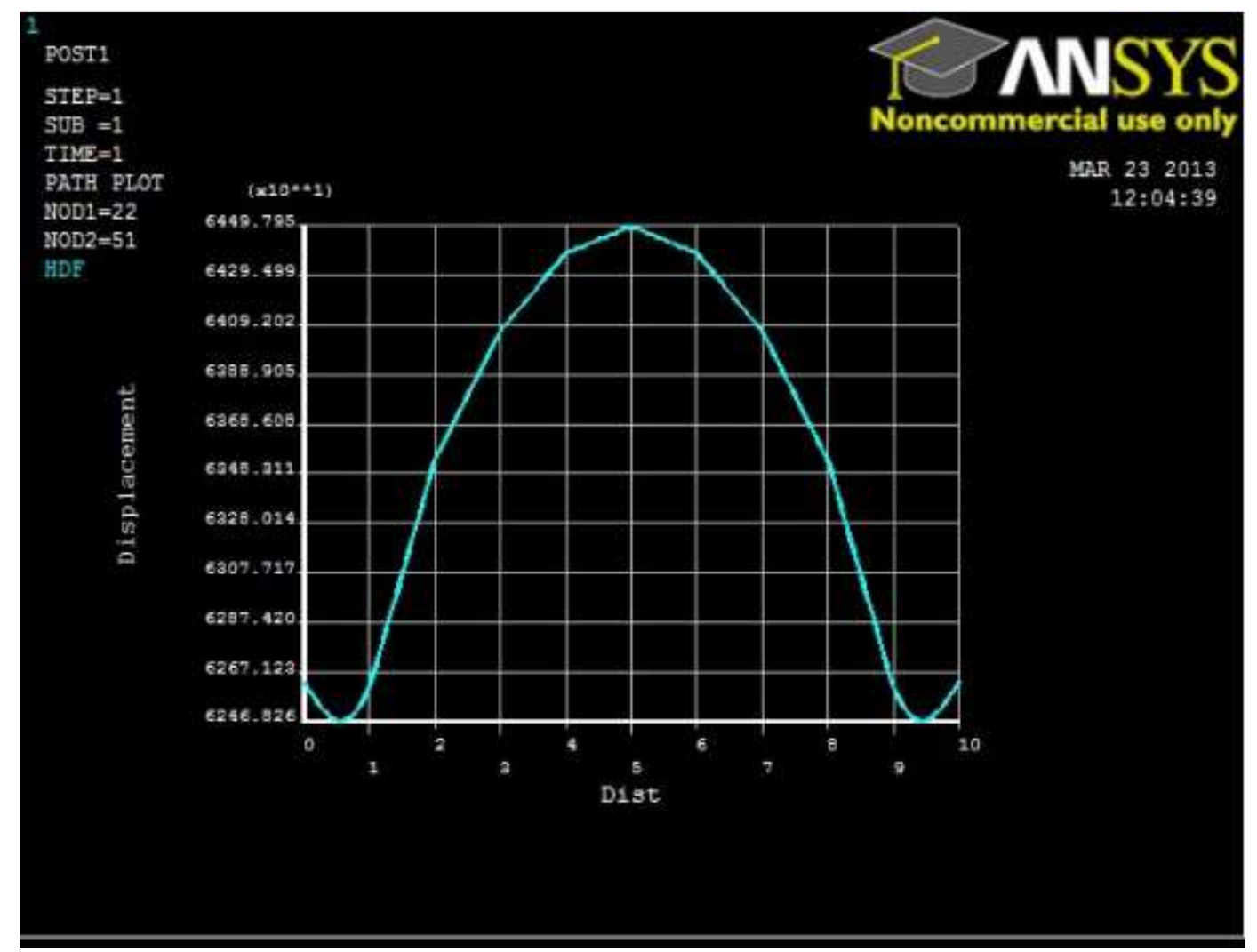

Figure 16. Distance Vs Stress Intensity.

\section{Results for Aluminium-7075}

At $200^{\circ} \mathrm{C}$

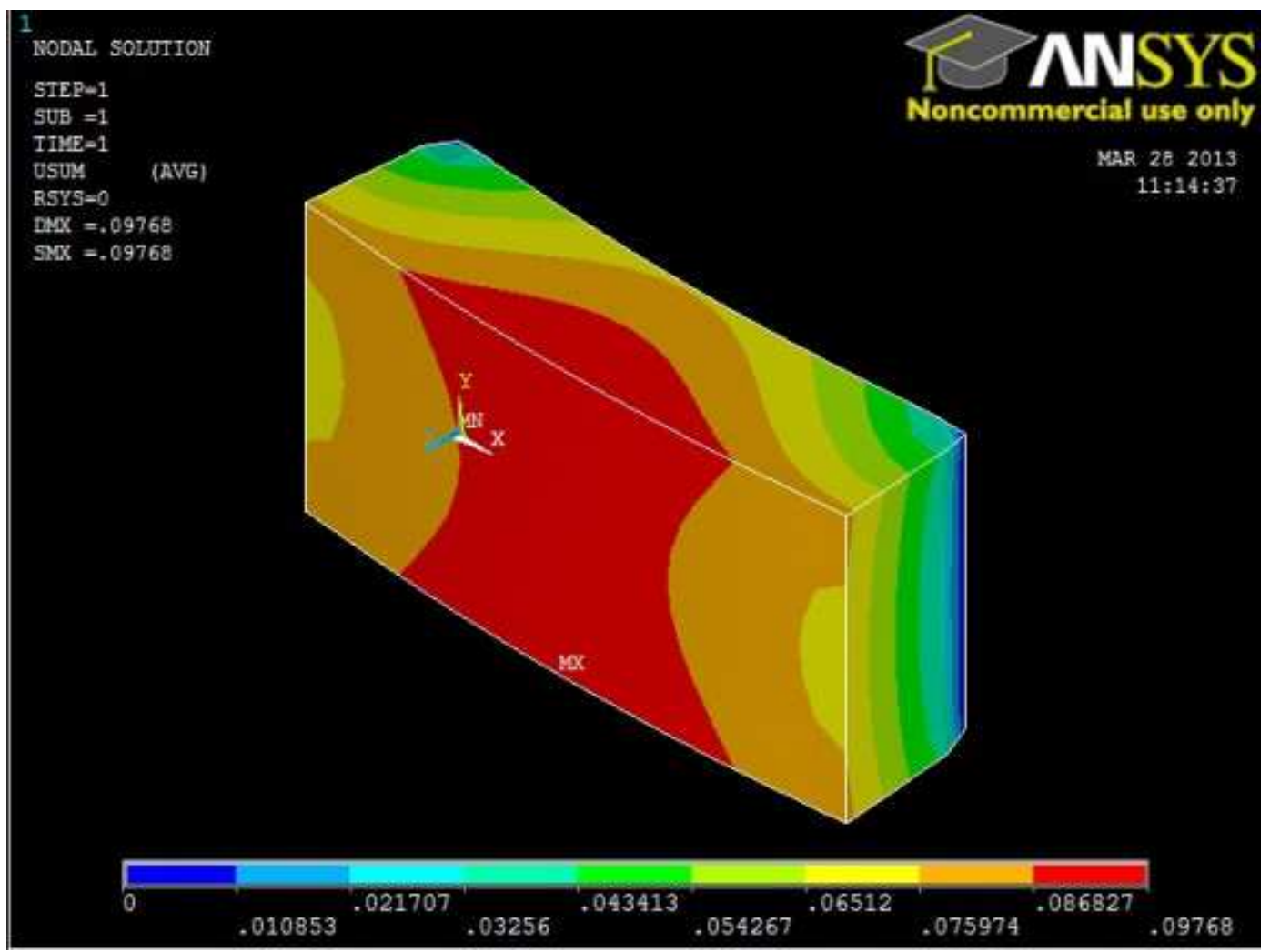

Figure 17. Showing Deformation- Aluminium-7075. 


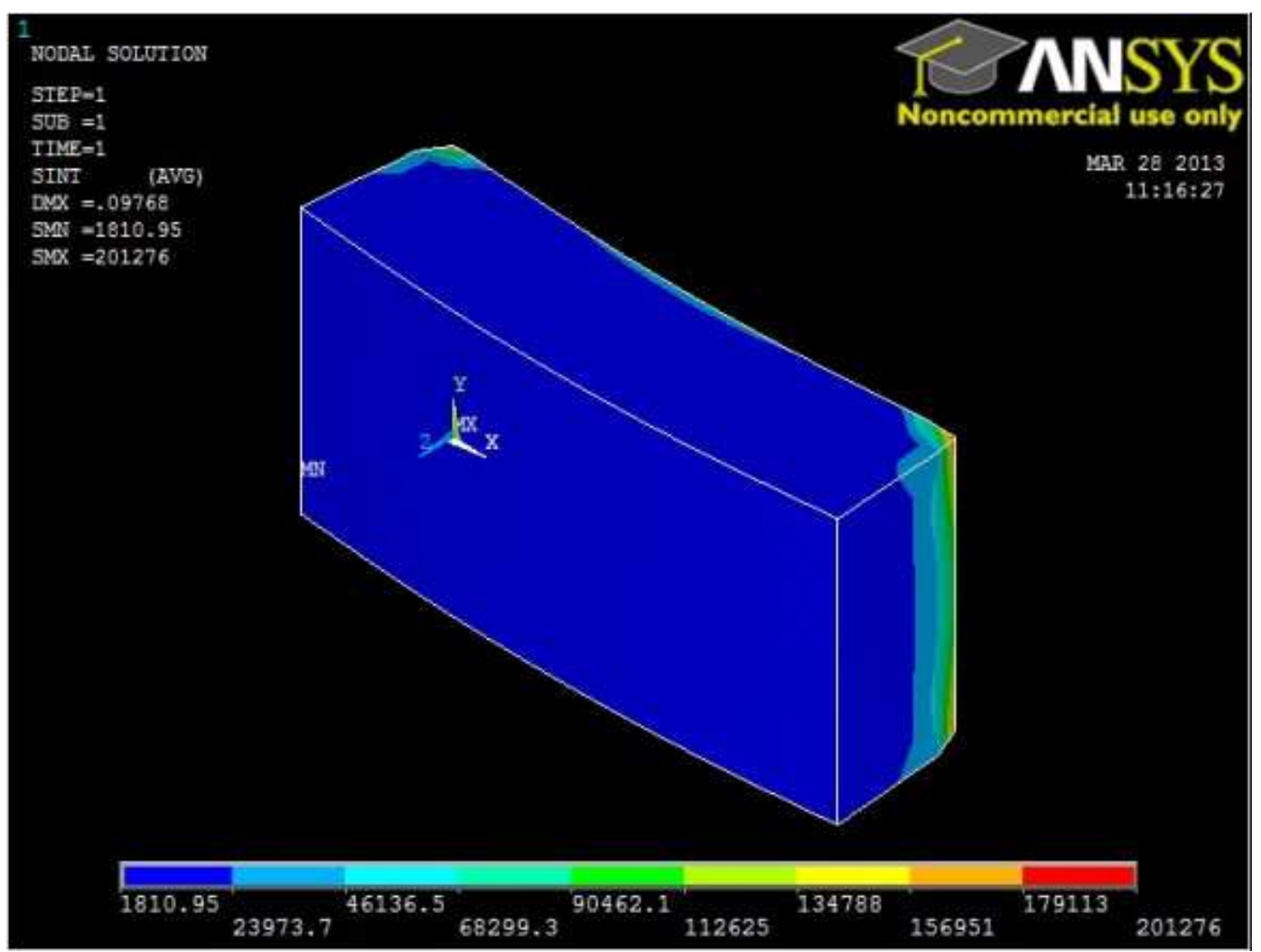

Figure 18. Showing Stress Intensity- Aluminium-7075.

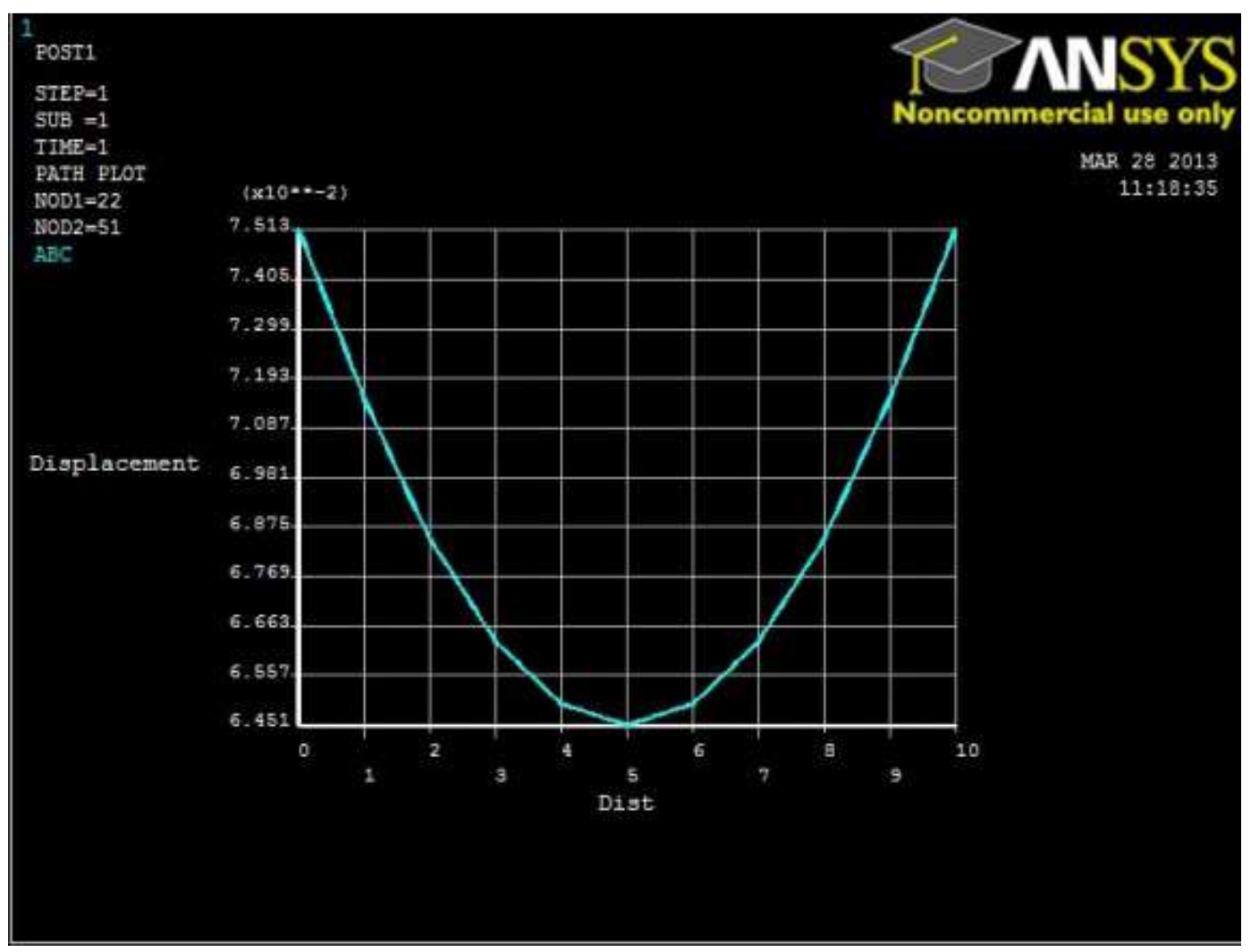

Figure 19. Showing Distance Vs Deflection. 


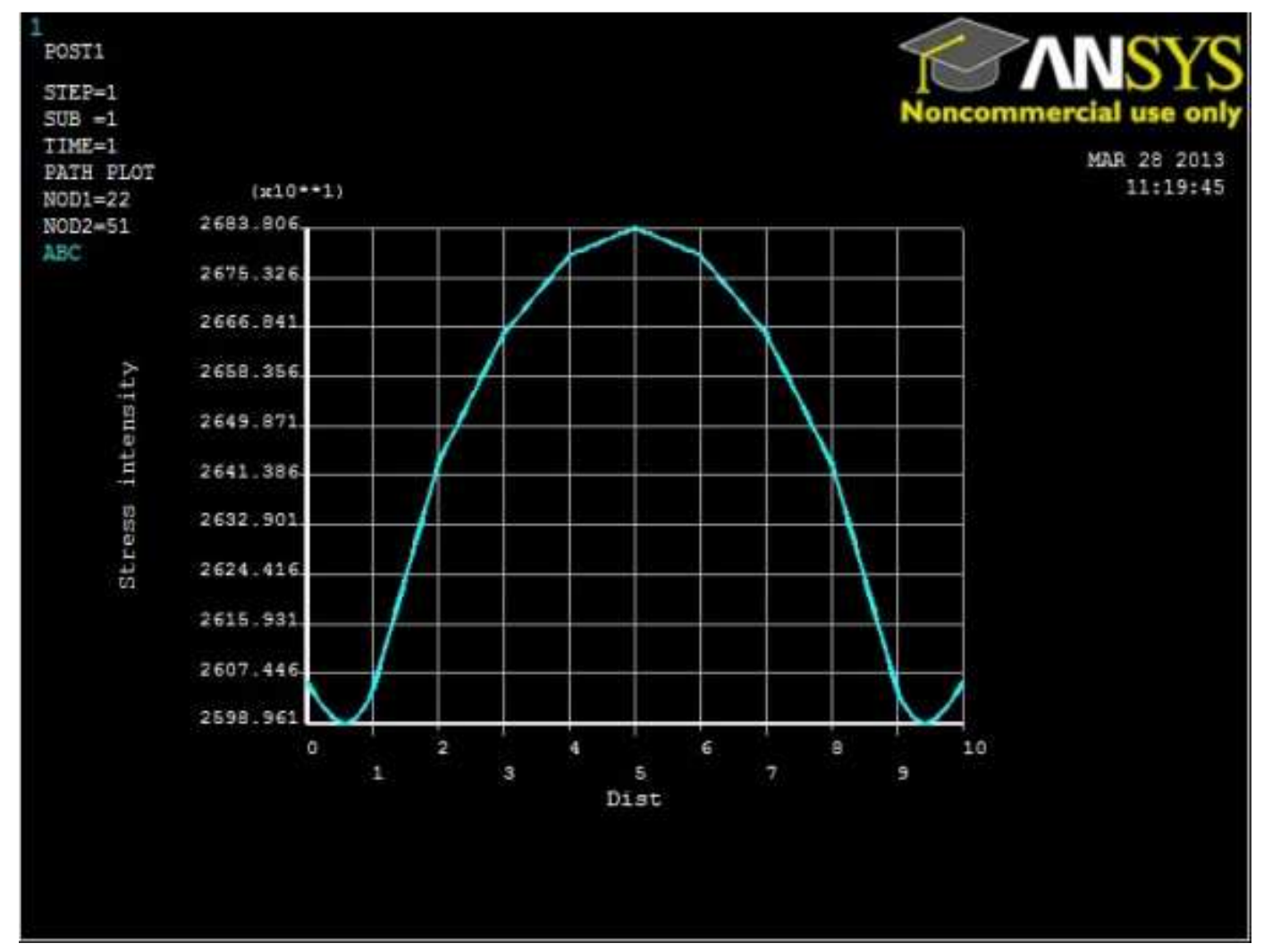

Figure 20. Showing Distance Vs Stress Intensity.

At $300^{\circ} \mathrm{C}$

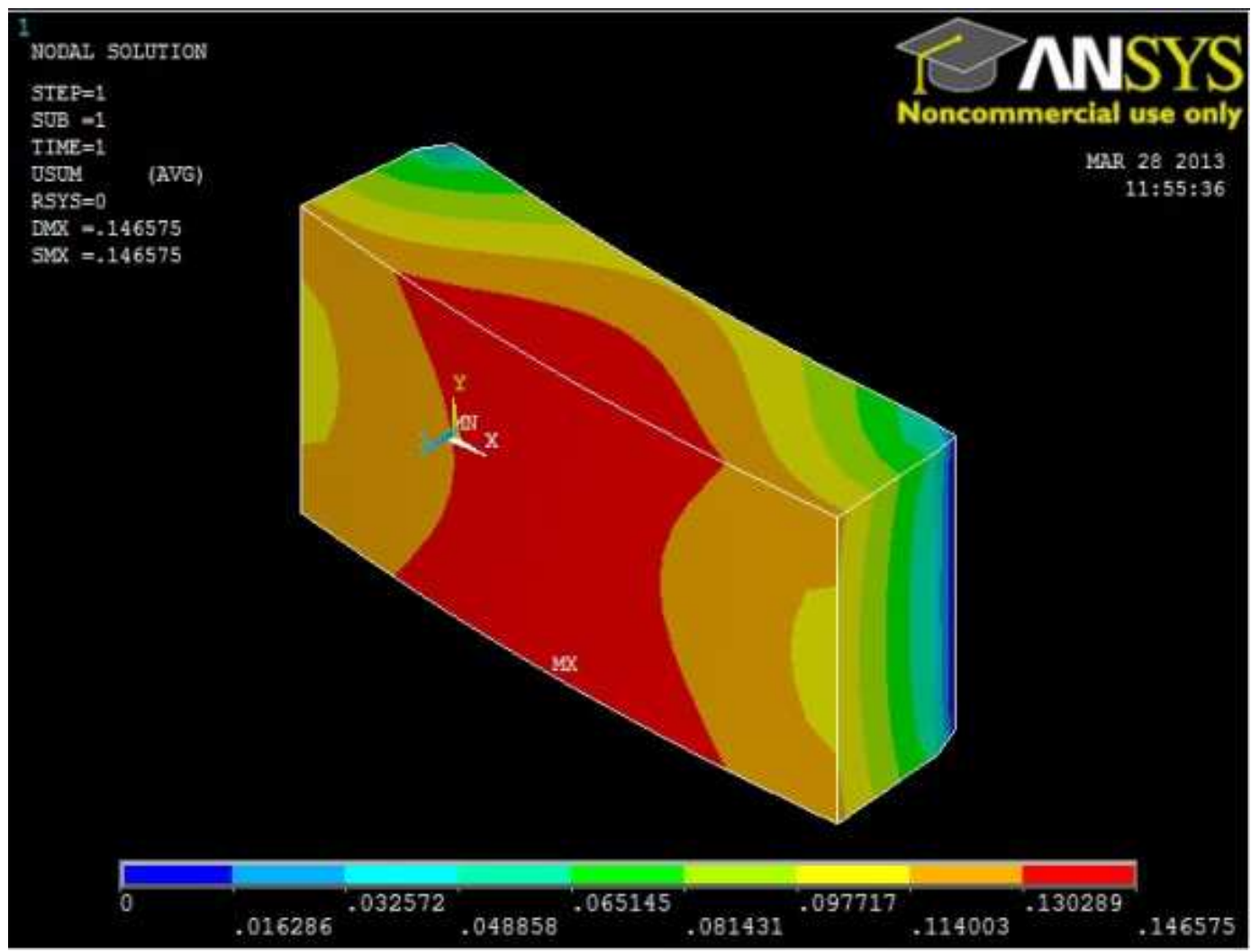

Figure 21. Showing deformation of Aluminium-7075. 


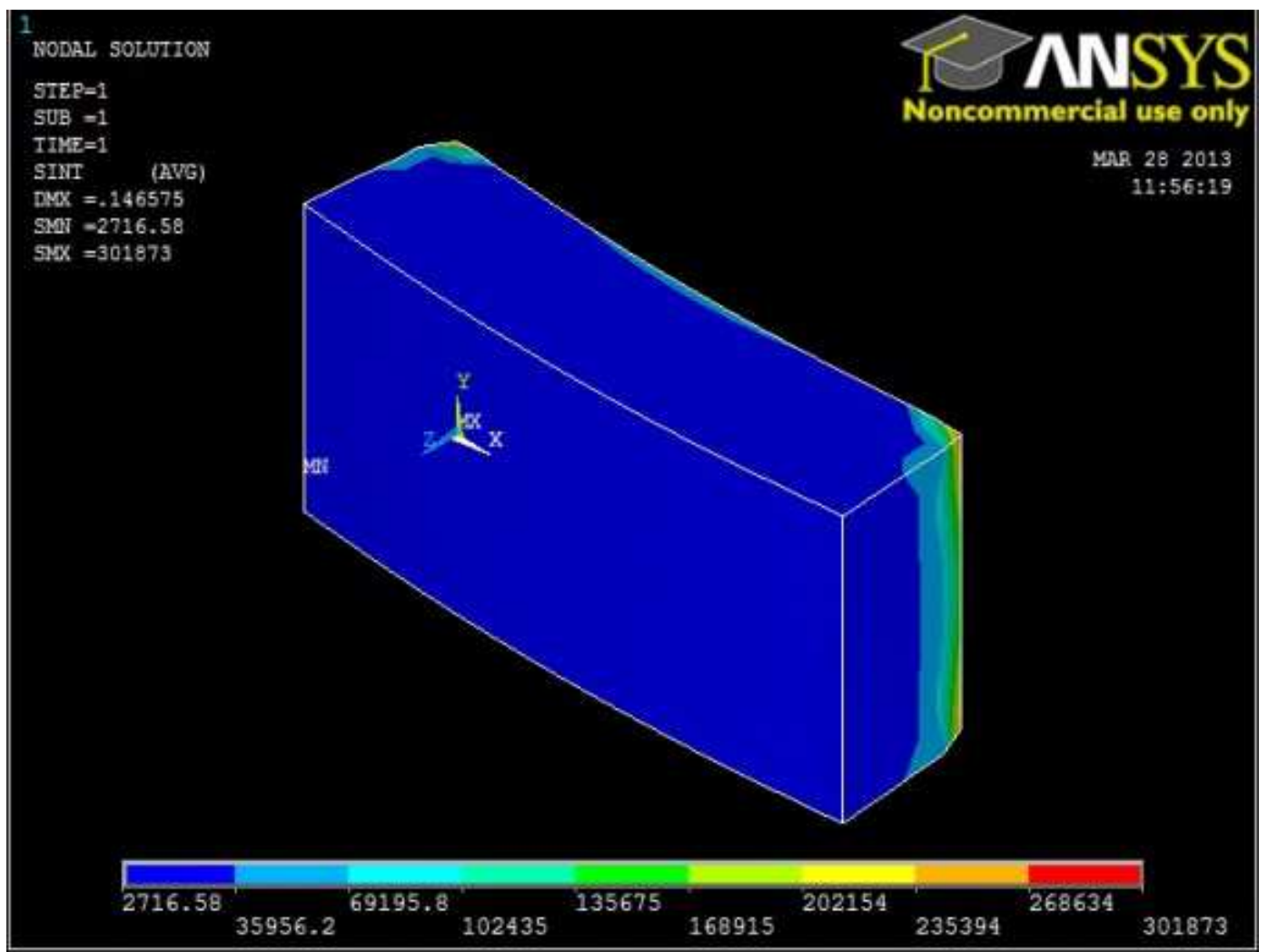

Figure 22. Showing Stress Intensity-Aluminium-7075.

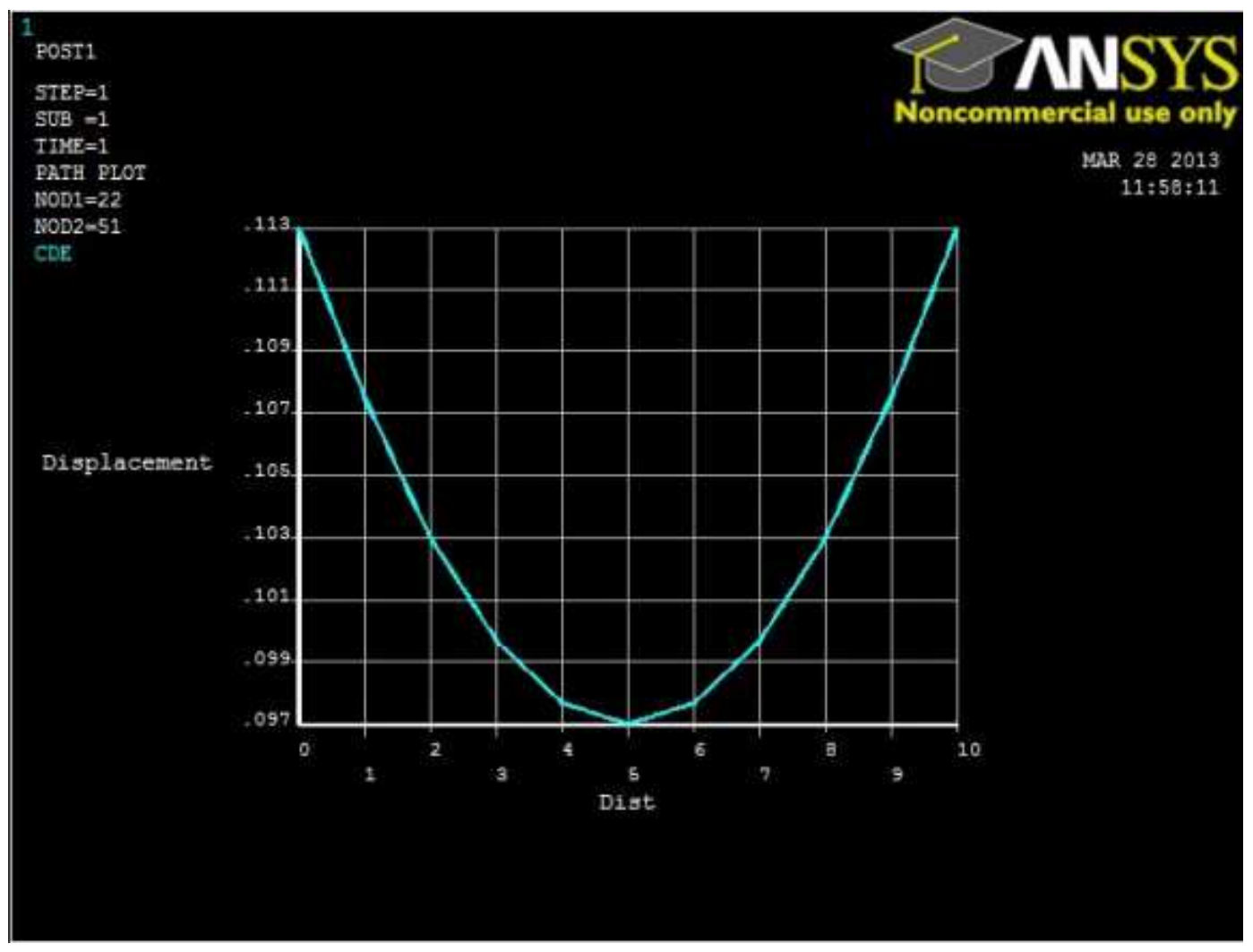

Figure 23. Distance Vs Deflection. 


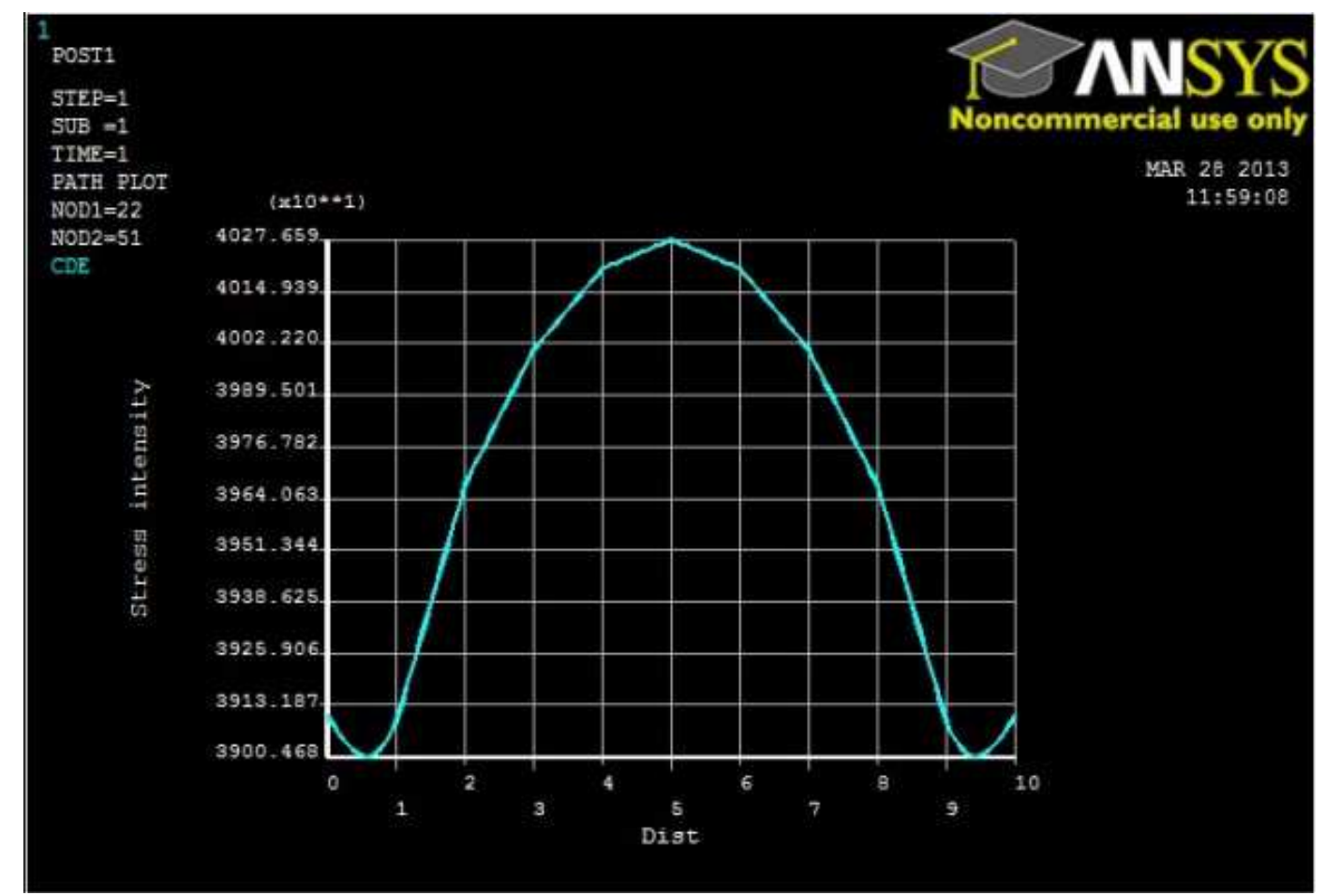

Figure 24. Distance Vs Stress Intensity.

At $400^{\circ} \mathrm{C}$

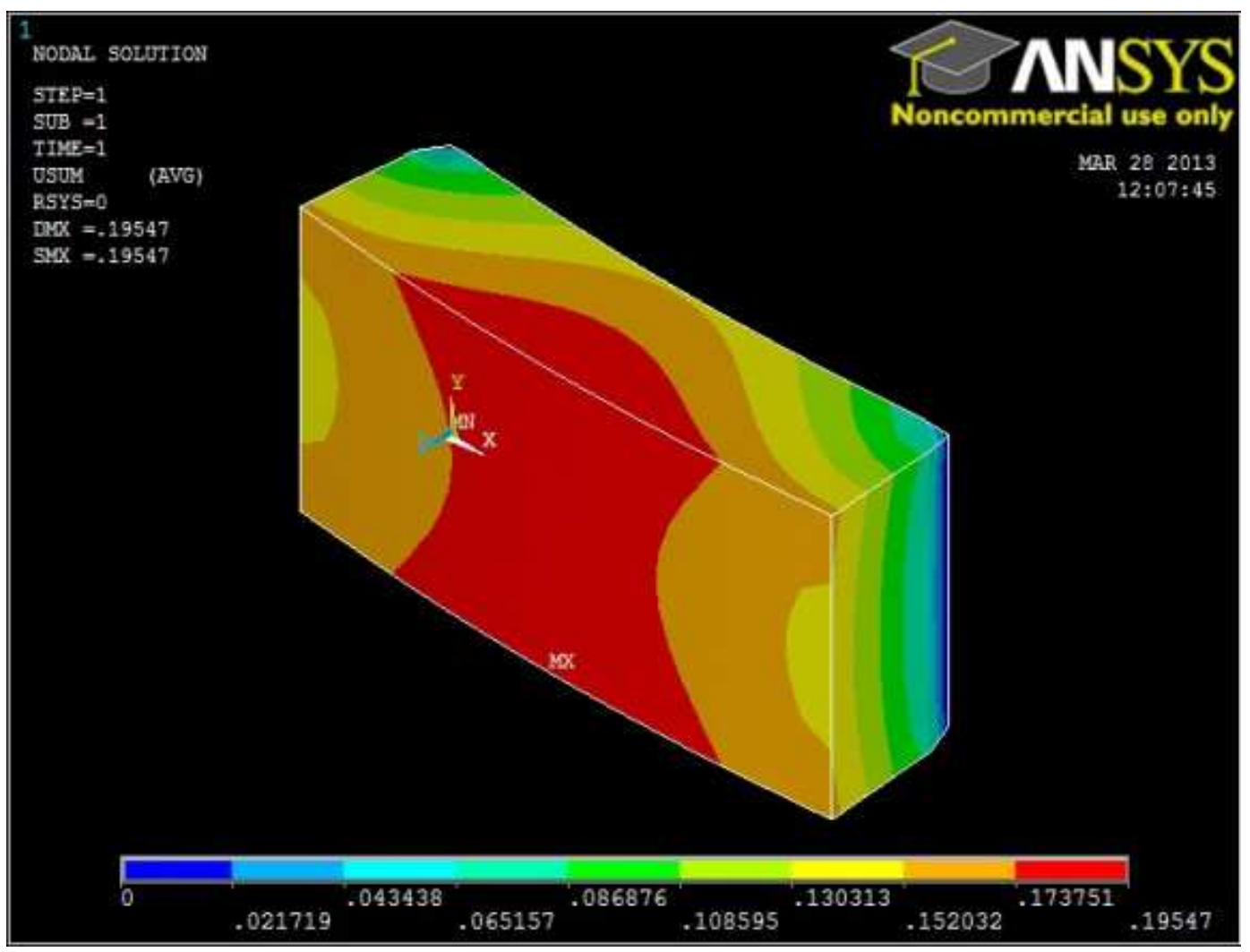

Figure 25. Showing Stress Intensity- Aluminium-7075. 


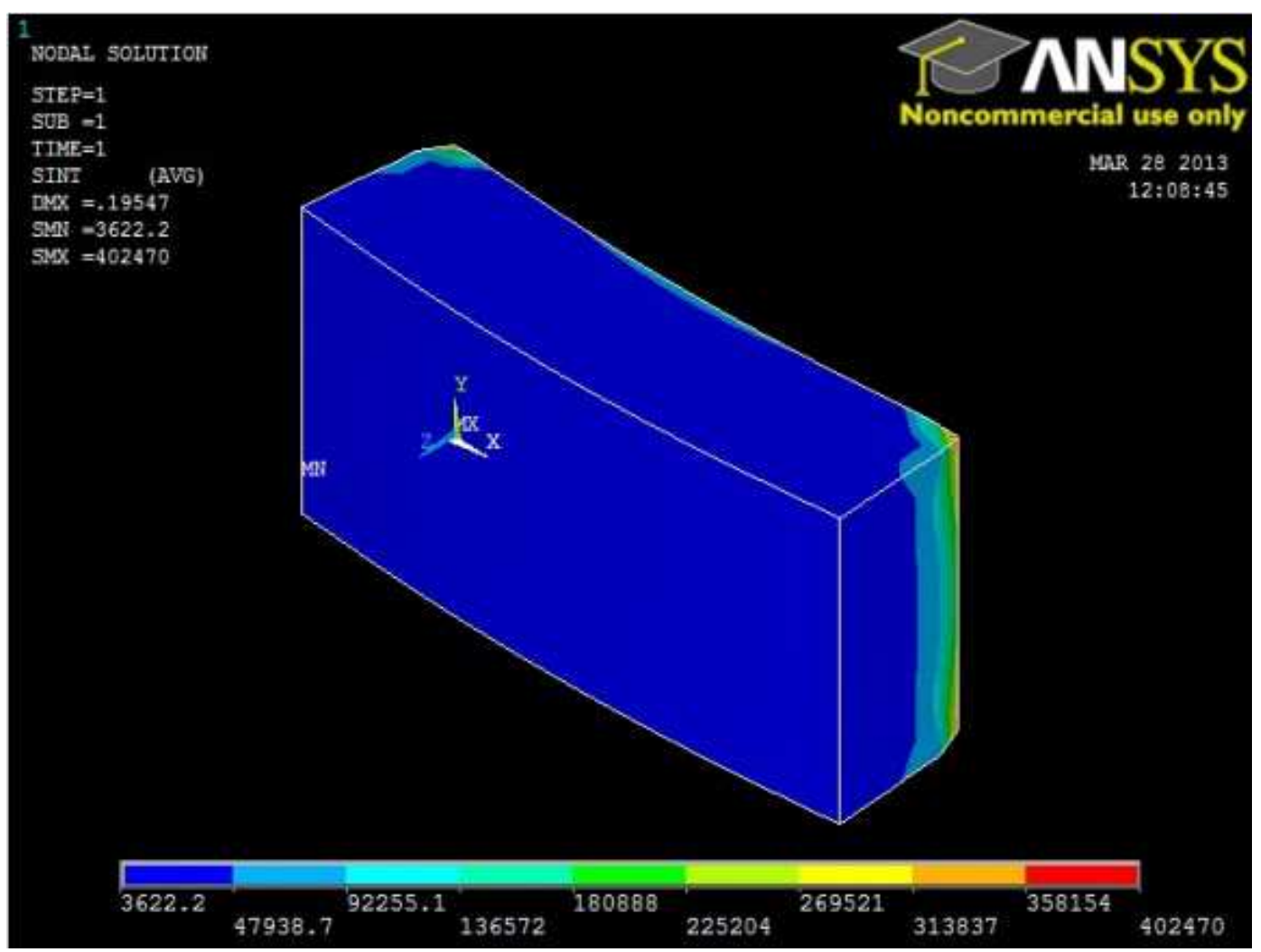

Figure 26. Showing Deformation - Aluminium-7075.

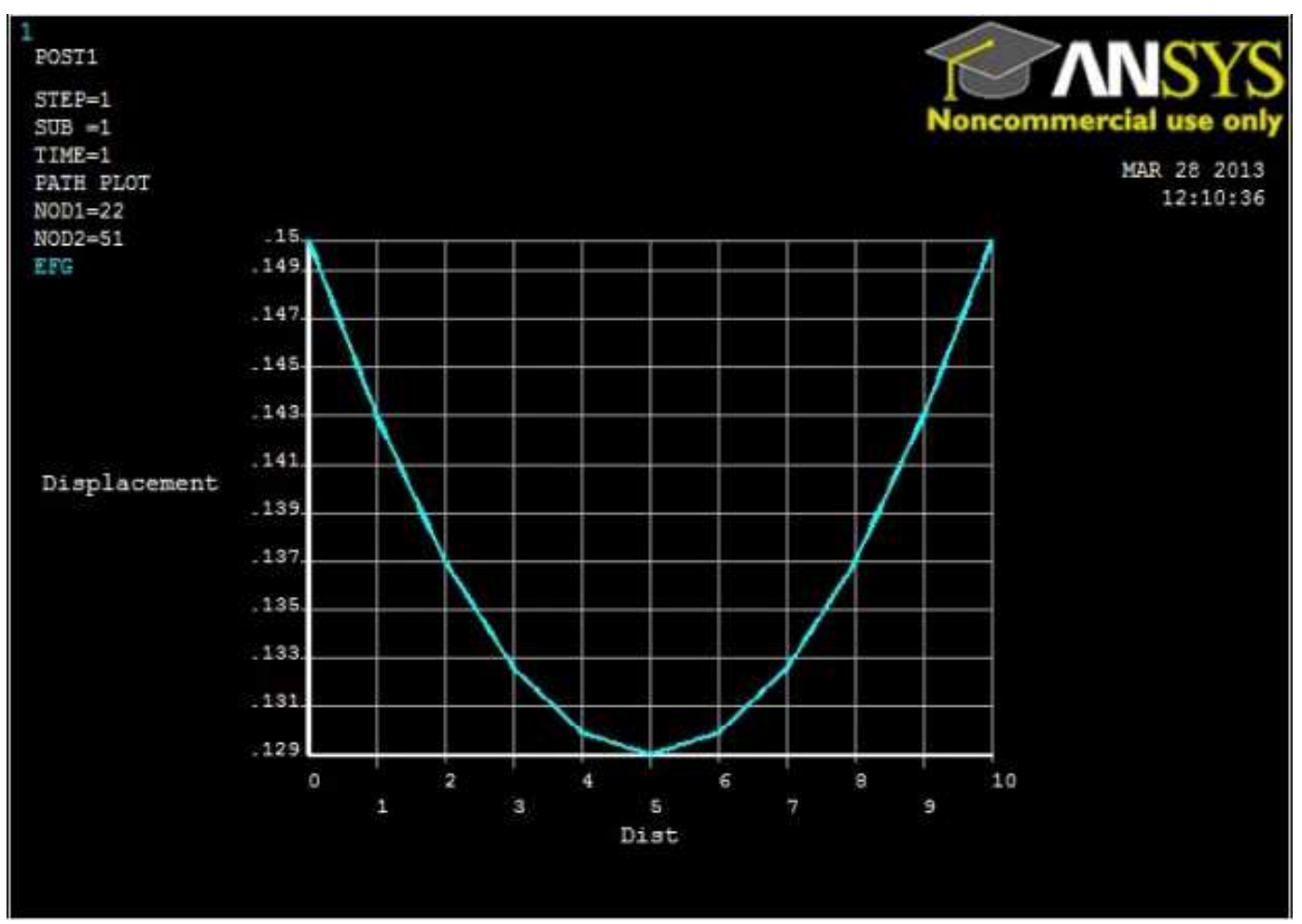

Figure 27. Showing Distance Vs Deflection. 


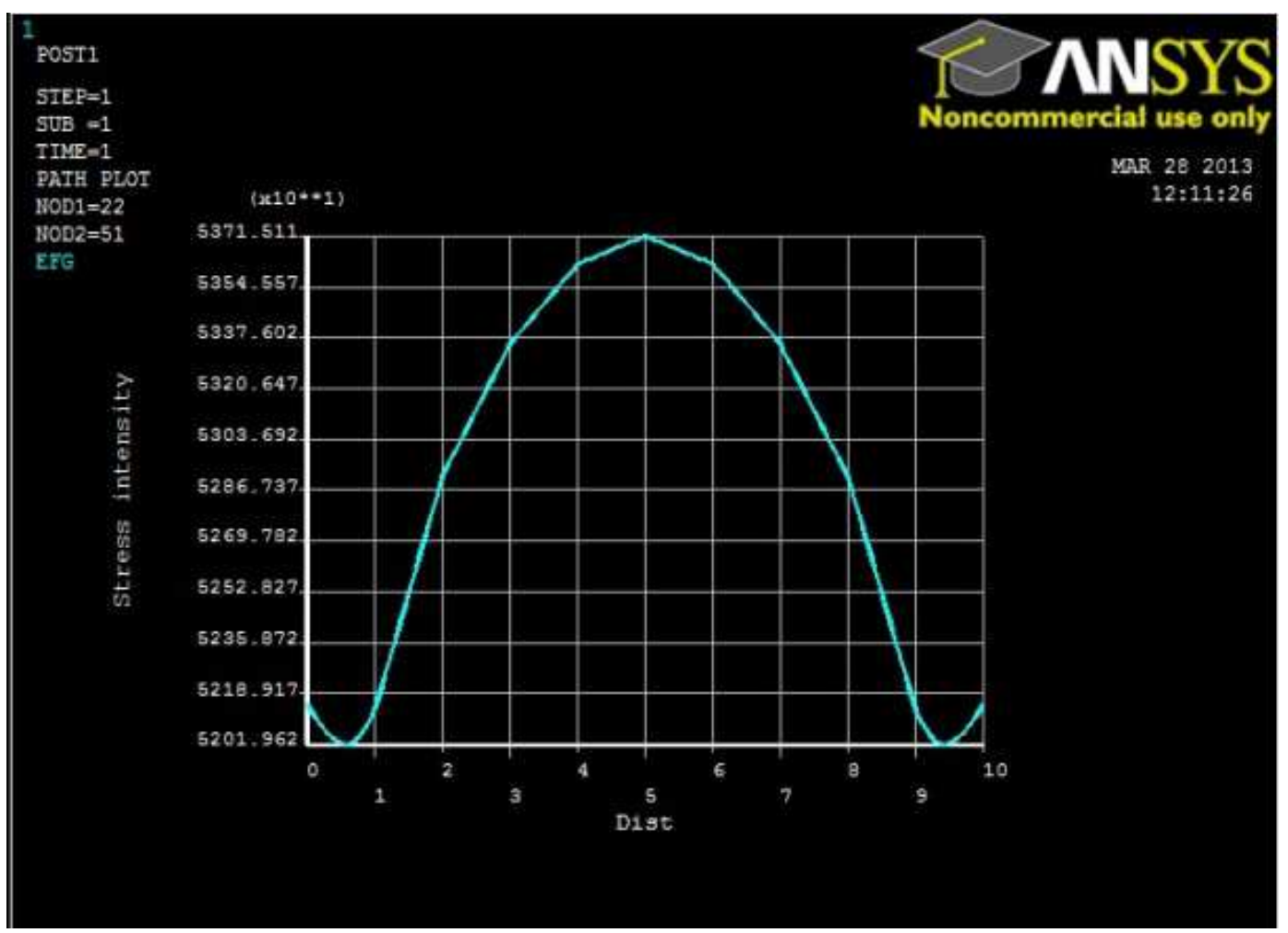

Figure 28. Showing Distance Vs Stress Intensity.

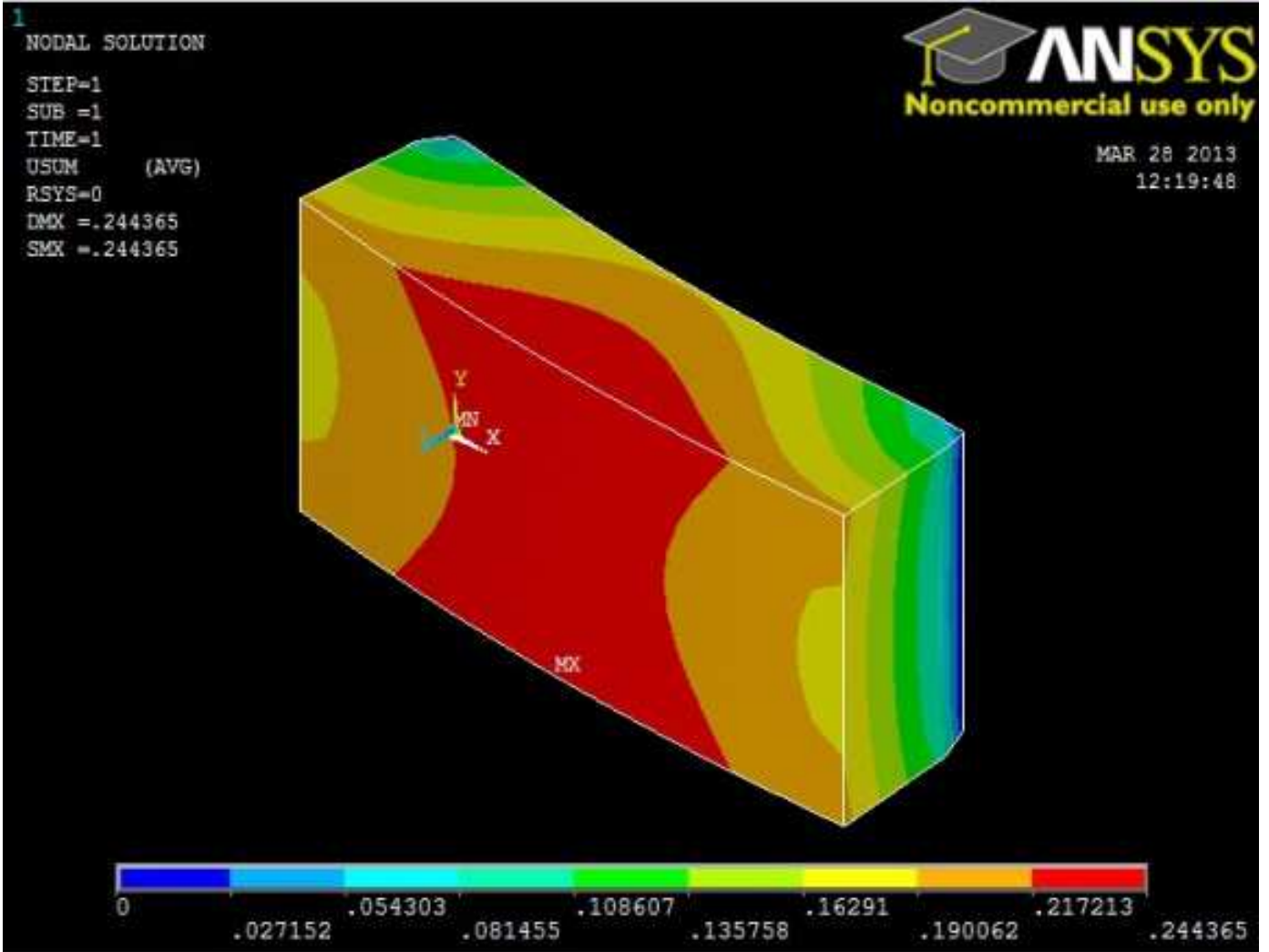

Figure 29. Showing deformation- Aluminium-7075. 


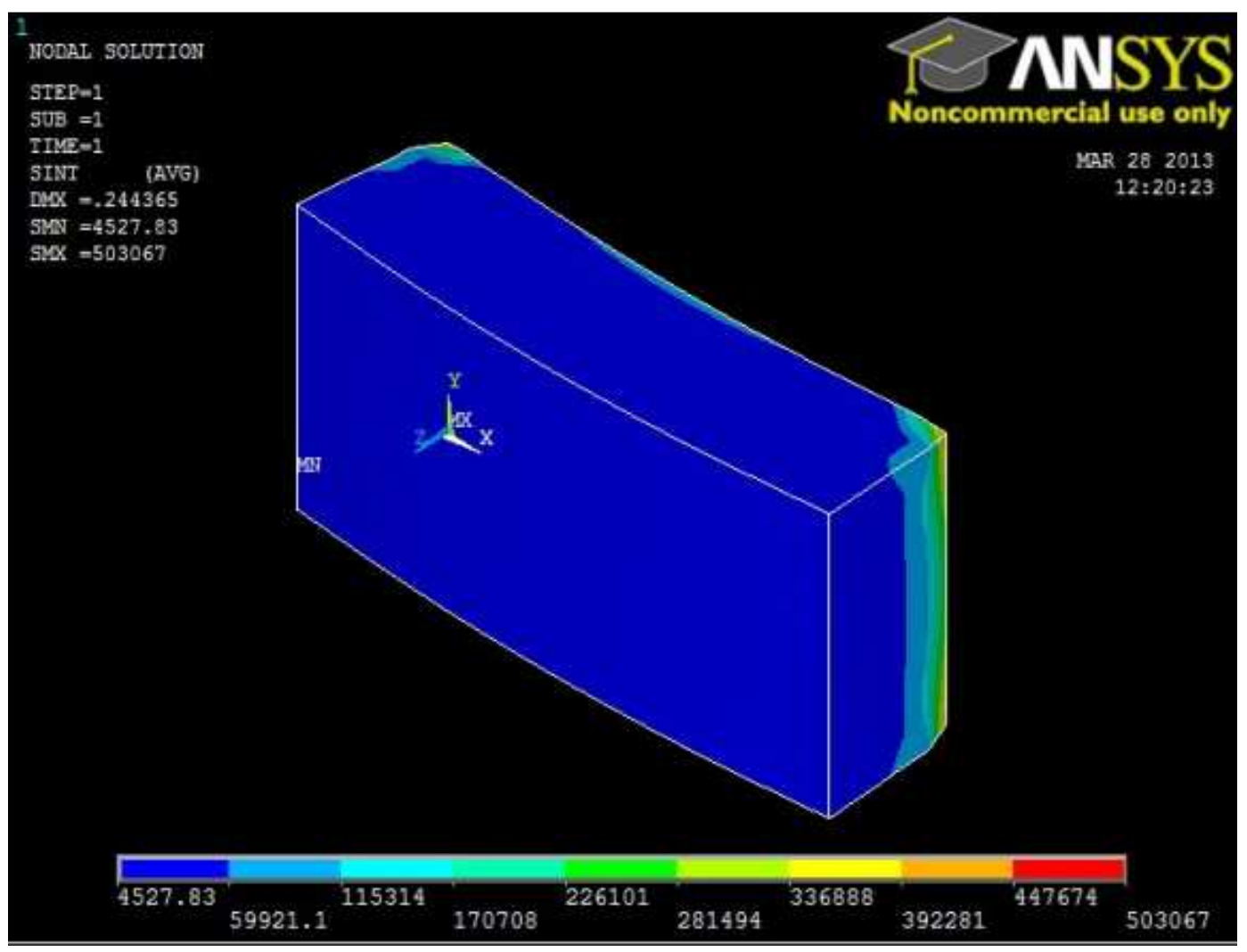

Figure 30. Showing Stress Intensity- Aluminium-7075.

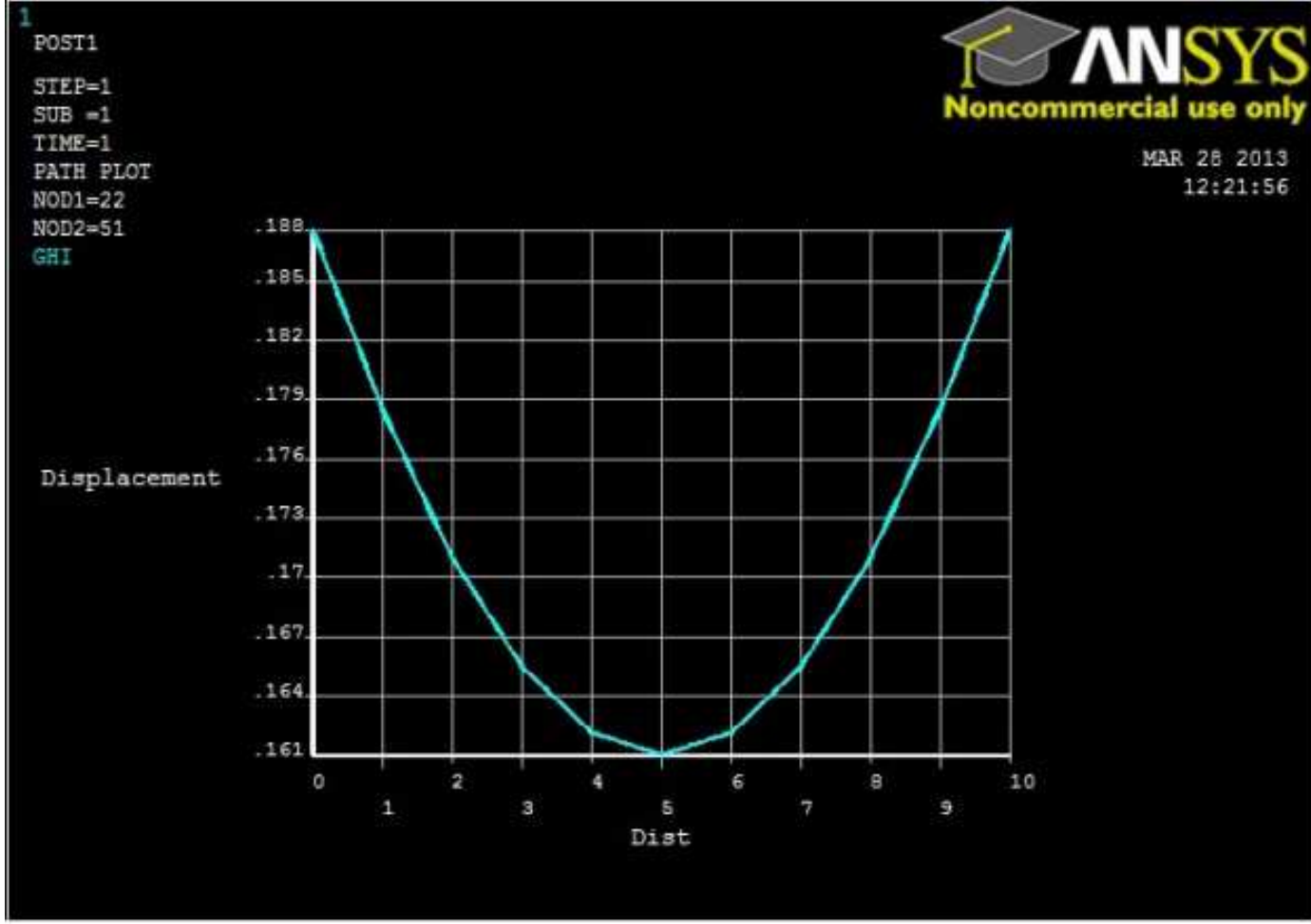

Figure 31. Showing Distance Vs Deflection. 


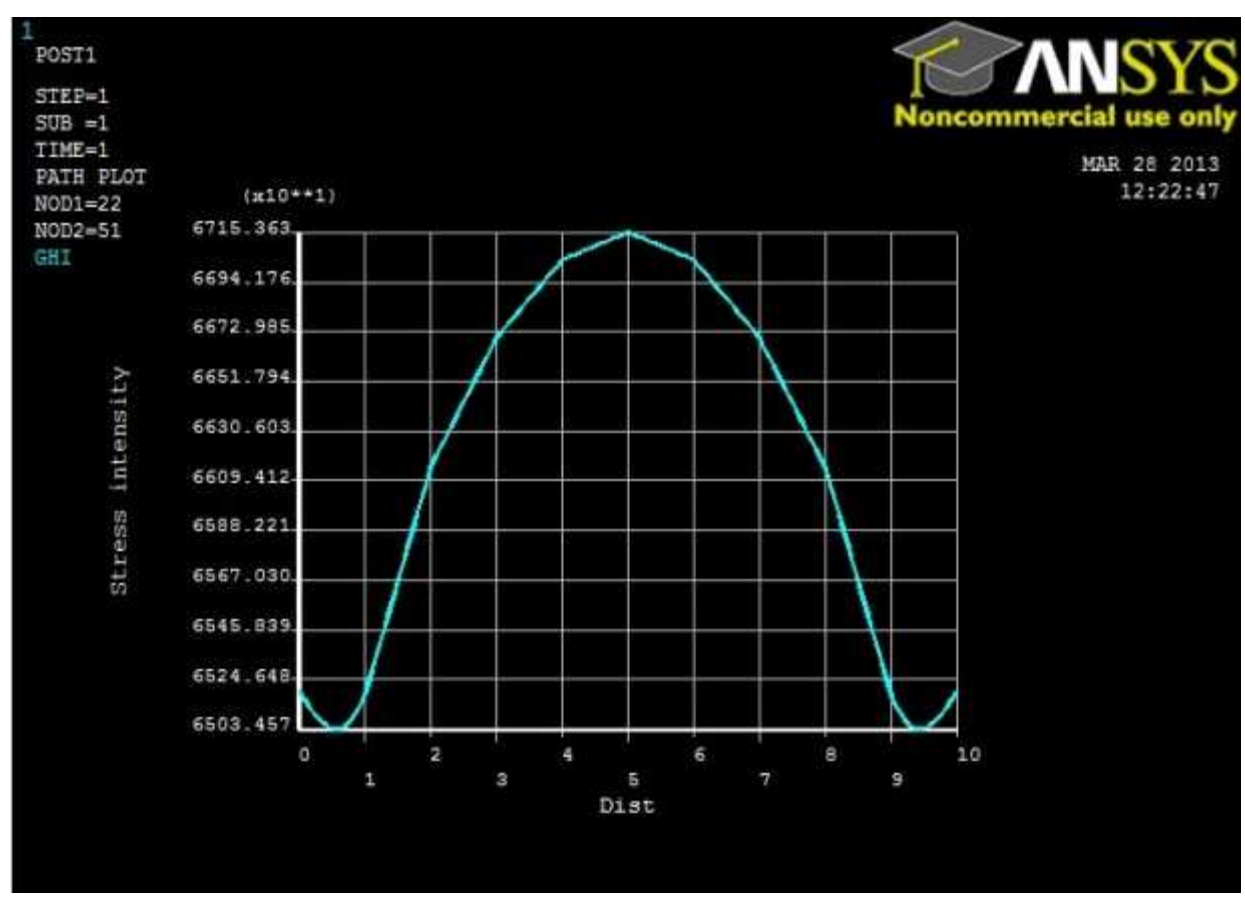

Figure 32. Showing Distance Vs Stress Intensity.

The induction principle was employed to decrease the heat-affected zone (HAZ) and improve process performance. Elevated temperatures not only increased the ductility but also decreased the spring back thus improving the quality of the product. The same material, tool and process parameters were used to produce cups under dynamic heating conditions. The two aluminum sheets were heated to different temperatures ranging from $200-500^{\circ} \mathrm{C}$. Under the uniform temperature condition, the cup height increased with increase in temperature. The multipurpose code of ANSYS is suitable for doing the finite element simulations of the formability of aluminium sheets at various temperatures since it can handle coupled thermo mechanical models.

It is found that the drawability of AA 6061 remains almost same and in the case of AA7075 it has stated to improve upto a temperature of $450^{\circ} \mathrm{C}$. At $450^{\circ} \mathrm{C}$ the cup height was almost same for both materials.

From $200^{\circ} \mathrm{C}$ to $250^{\circ} \mathrm{C}$ there is a sharp decrease in drawability of AA 6061. It may be because AA 6061 comprises magnesium and silicon as major alloying elements. As the temeperature increases these alloying elements restricts the drawability of alloy.

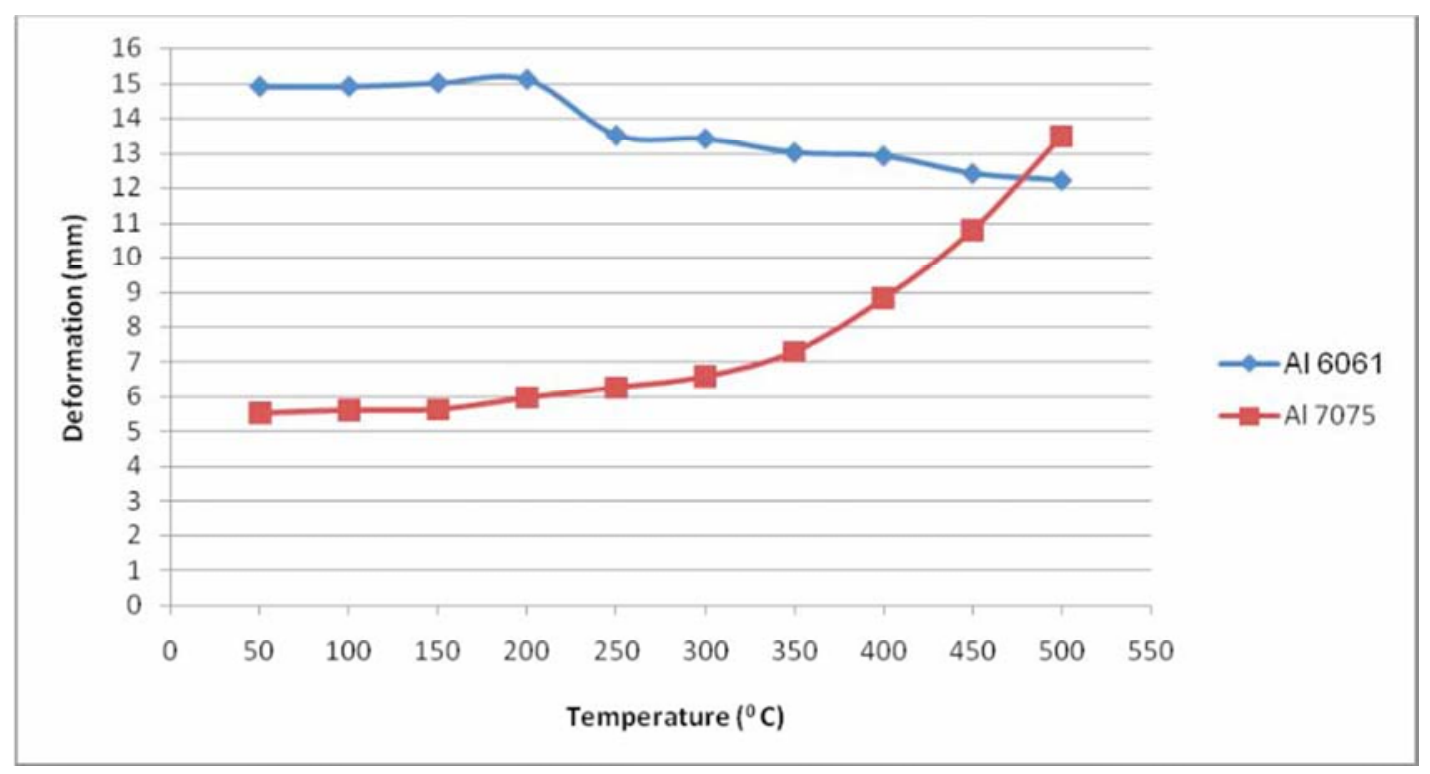

Figure 33. Showing Graph between Cup Height and Temperature.

It is thus infered that, if the temperature is maintained at $450^{\circ} \mathrm{C}$ for a blank with material combinations of AA6061 and AA7075, a more or less equal deformation can be achieved. 


\section{Conclusions}

In this study, forming of two different aluminum alloys has been simulated for V-cup drawing using ANSYS. Use of ANSYS makes the simulation process easy as the software is user friendly flexible and economical. ANSYS also gives accurate and precised results. It has been confirmed that higher cup depth is possible at elevated temperatures. It is inferred that AA 6061 is having better formability than AA 7075 at initial temperatures, but at elevated temperatures both the materials are having approximately equal formability. The optimum temperature at which both the blanks will have identical maximum uniform cup depths has been found during deep drawing.

\section{Future Scope}

More research is carrying on in the field of Tailor welded blanks. A tailor-welded blank is one part made up of different strengths or thicknesses of material joined at the factory usually by a laser weld. The sheets can be identical or they can have different thickness, mechanical properties or surface coatings. The main advantage of tailor-welded blank is the opportunity to place optimum thickness and strengths where they are needed the most. The complexity in using tailorwelded blanks arises in joining the materials. Advanced joining techniques like laser welding etc. are needed. By using TWB we can achieve higher strengths with minimum thickness.

\section{References}

[1] D. M. Finch, S. P. Wilson, J. E. Dorn. 1946. Deep drawing aluminium alloys at elevated temperatures. ASM Trans. 36: 254-289.
[2] S. Fulki. 1984. Deep drawing at elevated temperatures. Rep. Inst. Phys. Chem. Res. 24: 209-211.

[3] M. Miyagawa. 1959. Deep drawing methods at elevated temperatures. J. JSME. 62: 713-721.

[4] Y. Tozwa. 1960. Deep drawing methods by circumferential heating. J. Jpn. Soc. Tech. Plasticity. 1: 23-28.

[5] Y. T Keum, B. Y. Ghoo, R. H. Wagoner. 2001. 3 dimensional finite element analyses of non isothermalforming processes for non ferrous sheets. K. Mori (Ed). Simulation of Materials processing: Theory, Methods and applications. A. A. Balkema. Lisse. pp. 813-818.

[6] R. Neugebauer, T. Altan, M. Geiger, M. Kleiner, A. Sterzing. 2006. Sheet Metal Forming at Elevated Temperatures. Annals of the CIRP. Vol. 55/2.

[7] Srihari, M \& Shaik, Himam \& Vijaya Nirmala, S. (2016). Design And Analysis Of Crankshaft For 4-Stroke Deisel Engine. International Journal of Scientific Research and Modern Education (IJSRME). 1. 10.5281/ZENODO.158931.

[8] J Bagde, Bhumesh \& Raut, Laukik. (2013). FINITE ELEMENT ANALYSIS OF SINGLE CYLINDER ENGINE CRANK SHAFT. 6. 2231-1963.

[9] Shaik, Himam \& Reddy, Govardhana \& Hameed, Md. (2016). DESIGN REPORT OF A GO KART VEHICLE. International Journal of Engineering Applied Sciences and Technology, 2016. 1

[10] Serkan Toros, Fahrettin Ozturk, Ilyas Kacar. 2008. Review of warm forming of aluminum-magnesium alloys. Journal of materials processing technology. 207: 1-12.

[11] Shehata FA. 1986. Tensile behaviour of aluminium/magnesium alloy sheets at elevate temperatures. Sheet Met Indus. 63 (2): 79-81.

[12] S. Mahabunphachai, M. Koç. 2010. Investigations on forming of aluminum 5052 and 6061 sheet alloys at warm temperatures. Materials and Design. 31: 2422-2434. 